\title{
Role of FGFR2-signaling in the pathogenesis of acne
}

\author{
Bodo C. Melnik \\ Department of Dermatology; Environmental Medicine and Health Theory; University of Osnabrück; Germany
}

Abbreviations: AR, androgen receptor; DHT, dihydrotestosterone; EGF, epidermal growth factor; EGFR, epidermal growth factor receptor; FASN, fatty acid synthase; FGF, fibroblast growth factor; FGFR, fibroblast growth factor receptor; FRS2, fibroblast growth factor receptor substrate 2; GH, growth hormone; Gli, Gli transcription factor; GM-CSF, granulocyte macrophage colony stimulating factor; GPCR, G-protein coupled receptor; IGF-1, insulin-like growth factor-1; IGF1R, IGF-1 receptor; Ihh, indian hedgehog; IL-1 $\alpha$, interleukin-1 $\alpha$; IL-1 ra, interleukin-1 receptor antagonist; KGF, keratinocyte growth factor = FGF7; MAPK, mitogen-activated protein kinase; MC5R, melanocortin-5 receptor; MSH, melanocyte stimulating hormone; p63, transcription factor p63; PKC, protein kinase C; PI3K, phosphoinositide 3-kinase; Shh, sonic hedgehog; SREBP, sterol response element binding protein; TGF $\beta$, transforming growth factor beta; TGF $\alpha$, transforming growth factor $\alpha$; TK, tyrosine kinase

Key words: Apert syndrome, acne, comedogenesis, fibroblast growth factors, fibroblast growth factor receptor-2, insulin, insulin-like growth factor-1, interleukin- $1 \alpha$, nevus comedonicus, sebogenesis, unilateral acneiform nevus

It is the purpose of this review to extend our understanding of the fibroblast growth factor (FGF) receptor-2b-signaling network in the pathogenesis of acne. A new concept of the role of FGFR2b-signaling in dermal-epithelial interaction for skin appendage formation, pilosebaceous follicle homeostasis, comedogenesis, sebaceous gland proliferation and lipogenesis is presented. The FGFR2-gain-of-function mutations in Apert syndrome and unilateral acneiform nevus are most helpful model diseases pointing the way to androgen-dependent dermalepithelial FGFR2-signaling in acne. Androgen-mediated upregulation of FGFR2b-signaling in acne-prone skin appears to be involved in the pathogenesis of acne vulgaris. In organotypic skin cultures, keratinocyte-derived interleukin- $1 \alpha$ stimulated fibroblasts to secrete FGF7 which stimulated FGFR2b-mediated keratinocyte proliferation. Postnatal deletion of FGFR2b in mice resulted in severe sebaceous gland atrophy. The importance of FGFR2b in sebaceous gland physiology is further supported by the mode of action of anti-acne agents which have been proposed to attenuate FGFR2b-signaling. Downregulation of FGFR2bsignaling by isotretinoin explains its therapeutic effect in acne. Downregulation of FGFR2b-signaling during the first trimester of pregnancy disturbs branched morphogenesis and explains retinoid embryotoxicity. Insulin-like growth factor-1 (IGF-1), the mediator of growth hormone during puberty, intracts with androgen-dependent FGFR2b-signaling and links androgen- and

\footnotetext{
Correspondence to: Bodo C. Melnik; Professor of Dermatology; Department of Dermatology, Environmental Medicine and Health Theory; University of Osnabrück; Sedanstrasse 115; Osnabrück D-49090 Germany; Tel.: +05241.988060; Fax: +05241.25801; Email: Melnik@t-online.de

Submitted: 01/15/09; Accepted: 03/18/09

Previously published online as a Dermato-Endocrinology E-publication:

http://www.landesbioscience.com/journals/dermatoendocrinology/article/8474
}

FGF-mediated signal transduction important in sebaceous gland homeostasis. The search for a follicular defect in the dermalepithelial regulation of growth factor-signaling in acne-prone skin appears to be a most promising approach to clarify the pathogenesis of acne.

\section{Introduction}

Acne is a chronic inflammatory disease of the pilosebaceous unit, mostly affecting the sebaceous follicles. Major contributors of acne pathogenesis are abnormal follicular differentiation with increased cornification, enhanced sebaceous gland activity with hyperseborrhea, bacterial hypercolonization, inflammation as well as immunological host reactions. Sebaceous glands function continuously in excreting sebum to the skin surface with an average sebaceous cell transition time of 14 days. ${ }^{1-3}$ Androgens play an essential role for the stimulation of the size of sebocytes and sebum production as well as keratinocyte proliferation in the ductus seboglandularis and the acroinfundibulum., ${ }^{4,5}$ Exogeneous androgen excess or hyperandrogenism are associated with increased sebum production and severe acne. ${ }^{6,7}$ Acne-prone skin exhibits a higher androgen receptor (AR) density and higher $5 \alpha$-reductase type-I activity than uninvolved skin., ${ }^{8,9}$ Antiandrogens reduce the synthesis of sebaceous lipids and improve acne, whereas androgen-insensitive subjects who lack functional AR do not produce sebum and do not develop acne. ${ }^{10,11}$ Elevated levels of interleukin-1 $\alpha$ (IL-1 $\alpha$ ) have been detected in most open comedones of acne vulgaris. ${ }^{12}$ The pro-inflammatory cytokine IL-1 $\alpha$ is an important inducer of keratinocyte proliferation, hyperkeratinization, and reduced desquamation of comedo formation. ${ }^{13}$ Increased fibroblast growth factor receptor-2 (FGFR2)-signaling is associated with acne in Apert syndrome and has been suspected to be of pathophysiological importance in acne vulgaris. 


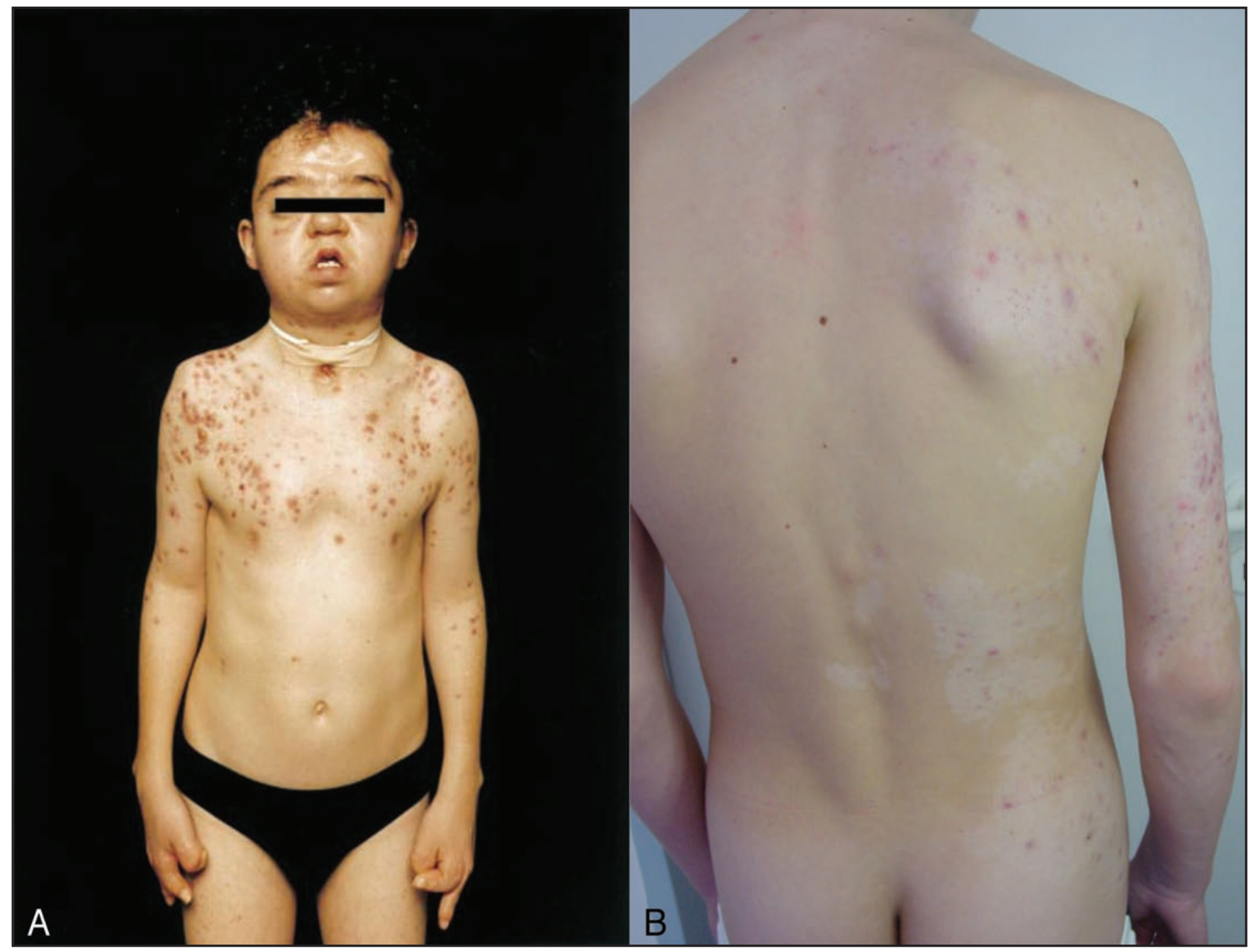

Figure 1. (A) Apert syndrome with early-onset severe nodulocystic acne extending to the forearms and thighs in an 11 -year-old boy. ${ }^{28}$ Two thirds of patients with Apert syndrome exhibit the Ser252Trp FGFR2 mutation, one third of patients the Pro253Arg FGFR2 mutation. (B) Unilateral segmental acneiform nevus in a 15-year old boy with a genetic mosaicism expressing the heterozygous mutation of Ser252Trp of FGFR2 in the affected skin areas following the lines of Blaschko. ${ }^{67}$ Photographs are kindly provided with permission by the publishers and authors.

A new concept will be presented recognizing the importance of FGFR2b-signaling for mesenchymal-epithelial interaction, androgen-dependence of FGFR2b-signaling and its downstream interaction of acne-inducing mediators like IL-1 $\alpha$, sonic hedgehog (Shh) and melanocortin-5 receptor (MC5R).

\section{Acne in Apert Syndrome}

Apert syndrome, also known as acrocephalosyndactyly, was first described in 1906, and is inherited in an autosomal dominant fashion, characterized by synostosis of extremities, vertebrae and skull. ${ }^{14}$ Irregular closure of the cranial sutures results in craniofacial deformity, turribrachycephalic skull, hypertelorism, a tendency towards proptosis of the eyes, dental abnormalities and cleft palate. Syndactyly of fingers and toes is also present. ${ }^{15-17}$ It was not until 1970 that Apert syndrome became known to dermatologists when Solomon described several patients with acne in an unusual distribution with lesions extending to the surface areas of the forearms. ${ }^{18}$
Moderate to severe acne is a dermatological hallmark of Apert syndrome, which often exhibits an early onset in puberty, therapy-resistance to antibiotics, but good response to oral isotretinoin. ${ }^{18-30}$ Patients with Apert syndrome often present oily skin. The acne clinically exhibits comedones, papules, pustules, furunculoid cysts and scars as seen in conglobate acne (Fig. 1A). ${ }^{18,19}$ On histological examination dilated hair follicles filled with keratinous plugs were observed. ${ }^{18,19}$ Follicular abscesses were noted in the upper and midcorium. ${ }^{19}$ Sebaceous lobules were reported to be larger and more numerous than normal. ${ }^{22}$ The dilated follicular infundibula extended to the mid-dermis where cut-cross-sections resembled open and closed comedones and infunibular follicular cysts. ${ }^{22}$ Plasma androgen levels and AR staining of sebaceous glands in Apert syndrome showed no difference in AR expression between patients and controls. ${ }^{27,28,30}$ 


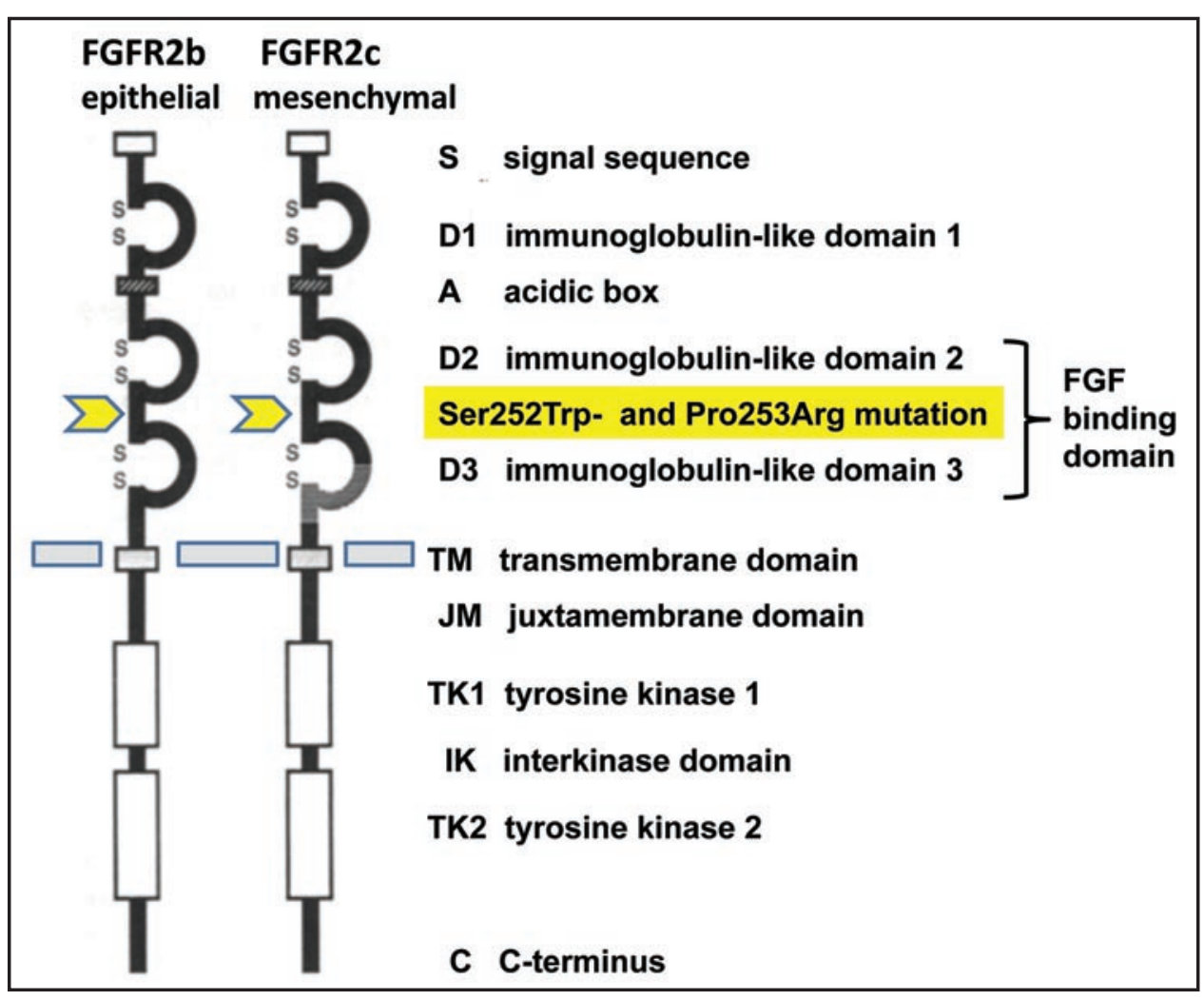

Figure 2. FGFR2 isoforms, FGFR2b and FGFR2c, generated by alternative splicing of FGFR transcripts. The immunoglobulin-like domains D2 and D3 constitute the FGF-ligand binding domains. Apert-mutations, Ser252Trp and Pro253Arg, are located in the interlinker domain (ILD) between D2 and D3 which lead to changes of ligand binding affinity, specificity and delayed lysosomal receptor degradation. between FGF7, FGF10 and FGFR2b. ${ }^{38}$ The lineage-specific expression of the FGFR2b and FGFR2c isoforms enables reciprocal interaction between epithelial and mesenchymal layers during development in response to different FGFs. ${ }^{32,39}$ Receptor dimerization leads to autophosphorylation of seven conserved intracellular tyrosine residues which serve as recruitment sites for $\mathrm{SH} 2$ domain-containing proteins to initiate downstream signaling. ${ }^{33,40}$ The fibroblast growth factor receptor substrate 2 (FRS2) serves as docking site for a number of intracellular proteins including Grb2, SHP2 and c-Cbl. ${ }^{41-45}$ The recruitment of the Ras activator SOS through a Grb2/ FRS2 complex is thought to be the primary route for activation of extracellular signal regulated protein kinase (ERK) pathways. ERKs are a subclass of mitogen-activated protein kinases (MAPKs); phosphorylated forms of ERKs translocate to the nucleus where they activate transcription factors involved in cell cycle control like cyclin D1 and regulate expression of cytokines like interleukin-1 $\alpha$ (IL-1 $\alpha){ }^{46,47}$ Besides activating the MAPK cascade,

\section{FGFR2 Signal Transduction Pathways}

For the understanding of the biological role of FGFR2 mutation in Apert syndrome, an introduction into the molecular biology and cellular signaling of FGFRs is helpful. The FGFRs comprise a family of related but individually distinct tyrosine kinase receptors. At least 22 distinct FGFs mediate a variety of cellular responses during embryonic development and tissue homeostasis in the adult organism. ${ }^{31}$ FGFRs have a similar protein structure, with three immunoglobulin-like domains (D1-D3) in the extracellular region, a single membrane spanning segment, and a cytoplasmic tyrosine kinase with an ATP-binding domain (Fig. 2). Four FGFRs designated FGFR1 to FGFR 4 have been identified. ${ }^{32}$ FGFRs bind in clusters to heparan sulfate proteoglycans, enabling the ligands to cross-link the receptors. ${ }^{33}$ An important feature of the FGFR family is that a variety of FGFR isoforms are generated by alternative splicing. ${ }^{32}$ Two splice variants of FGFR2 are designated FGFR2b and FGFR2c. FGFR2b is expressed exclusively in epithelial cells and binds FGF7 and FGF10, but not FGF2. ${ }^{34}$ FGFR2b is localized mainly in the suprabasal spinous layer of the epidermis and sebocytes and plays a crucial role in controlling epithelial proliferation and differentiation. ${ }^{35-37}$ The mesenchymal isoform FGFR2c binds FGF2, FGF4, FGF6, FGF9, FGF17 and FGF18, but not FGF7 and FGF10. ${ }^{34}$ Both, the D2- and D3-immunoglobulinlike domains of FGFR2b contribute to the exceptional specificity activated FGFRs also activate the phospholipase C- $\gamma /$ protein kinase $\mathrm{C}(\mathrm{PKC})$ and the phosphoinositide-3-kinase (PI3K)/Akt signaling cascades (Fig. 3). ${ }^{48}$ PI3K/Akt regulate the expression of sterol response element binding protein-1 (SREBP-1), a most important transcription factor in lipogenesis.

After binding of FGF7 to FGFR2b, the receptor complex is ubiquitinylated and degraded, whereas FGF10 binding targets the receptor to the recycling endosomes. ${ }^{49,50}$ Under physiological conditions, FGFR2 signaling is terminated by transient ligand-dependent endocytosis of FGFR2 and FRS2 into intracellular vesicles and lysosomal FGFR2-degradation by FGFR2-ubiqitination. ${ }^{49,51}$

\section{FGFR2-Mutations in Apert Syndrome}

Apert and Crouzon syndromes are among the most common craniosynostosis syndromes and are both caused by mutations in FGFR2. ${ }^{52}$ Apert syndrome (MIM 101200) results from specific heterozygous missense mutations at two adjacent residues of the FGFR2 gene, Ser252Trp or Pro253Arg, predicted to lie in the linker region between D2- and D3-immunoglobulin-like regions of the FGFR2-ligand binding domain (Fig. 2). ${ }^{53,54}$ The mutations increase the FGF-binding affinity and are thus gainof-function mutations. ${ }^{53,54}$ Both mutations have been found to introduce additional interactions between FGFR2 and FGF2, thereby augmenting FGF2-FGFR2 affinity. ${ }^{55}$ Wildtype and 
Apert-type FGFR2 form a complex with FGF ligands with a stoichiometry of 2:2 (ligand:receptor). ${ }^{54}$ Distinct variations in the gain-of-function mutations explain the phenotypical variability of Apert syndrome. Patients with the Ser252Trp-mutation present more frequently with cleft palate, whereas patients with the Pro253Arg-mutation exhibit more severe syndactyly. ${ }^{56,57}$ Two-thirds of patients with Apert syndrome exhibit the Ser252Trpmutation, and nearly one third the Pro253Arg-mutation. 58,59

Both mutations of FGFR2 in Apert syndrome break one of the cardinal rules governing ligand specificity of FGFR2. ${ }^{60}$ The Ser252Trp-mutation allows the mesenchymal splice form of FGFR2 (FGFR2c) to bind and to be activated by the mesenchymally expressed ligands FGF7 and FGF10 and the epithelial splice form of FGFR2 (FGFR2b) to be activated by FGF2, FGF6 and FGF9. ${ }^{60}$ It has been proposed that an increase in mutant FGFR2c binding to multiple FGFs may result in craniosynostosis, whereas binding of mutant FGFR2c to FGF10 may result in severe limb pathology. Structural and biophysical analyses also showed that Apert syndrome mutations in FGFR2b also enhanced and violated FGFR2b ligand binding affinity and specificity, respectively. ${ }^{61}$ From these observations it has been concluded that elevated mutant FGFR2b-signaling may account for the dermatological manifestation of Apert syndrome. ${ }^{61}$

As Apert syndrome is an autosomal dominant heterozygous disease affecting the paternal allele of FGFR2 in most cases, the unaffected maternal allele of FGFR2 will allow normal signaling. ${ }^{62}$ FGF-binding to FGFR2 induces a dimeric form of the receptor complex. ${ }^{63}$ Three types of FGFR2-dimers have to be expected on the surface of the cell membrane: completely normal FGFR2dimers in $25 \%$, hybrids of normal and mutant receptors in 50\%, and completely mutant dimers in $25 \%$. The gain-of-function mutation of FGFR2b in Apert syndrome will allow normal signaling to the epidermis mediated through FGF7 and FGF10 in about 25\% of receptors, whereas $75 \%$ of the receptor dimers are activated by increased FGF2 binding affinity and will primarily signal through FGF2 and other epithelial cell derived FGFs. Once activated, FGFRs signal downstream via adapter proteins and cytosolic kinases like FRS2, Grb2, Sos, Ras, Raf, MAPKK (Mek), MAPK (Erk) to modify responsive target genes. ${ }^{32}$ Intriguingly, a threefold increased expression of IL-1 $\alpha$ was observed in Ser252Trp-FGFR2mutated Apert osteoblasts. ${ }^{47}$

\section{Animal Model of Apert Syndrome}

A knock-in mouse model with a FGFR2+/Ser252Trp-mutation showed midline sutural defect and craniosynostosis with abnormal osteoblastic proliferation and differentiation. ${ }^{64} \mathrm{~A}$ mouse model was developed with conditional expression of FGFR2 with the Ser252Trp missense mutation. ${ }^{65}$ These mice carrying the activated mutant form of FGFR2 showed malformations mimicking the abnormalities found in patients with Apert syndrome, including dome-shaped skull, widely spaced eyes, premature closure of the coronal suture, and underdeveloped midface. Co-expression of a small hairpin RNA targeting the mutant FGFR2 completely prevented these malformations and restored normal FGFR2 signaling as shown by normal levels of Erk1/Erk2-phosphorylation and reduced expression of Erk1 target genes. ${ }^{65}$ Treatment of pregnant mice with a pharmacologic inhibitor of Mek1/Mek2 blocked the phosphorylation and activation of Erk1/Erk2 and resulted in the recovery of Ser252Trp-FGFR2 mutant pups that were indistinguishable from wildtype. ${ }^{65}$ This animal model convincingly demonstrates that the Ser252Trp-FGFR2-mutation leads to exaggerated downstream signaling and shows that Erk (MAPK)activation plays a pathologic role in the craniosynostosis resulting from Ser252Trp mutation of FGFR2. 


\section{Cell Model of Apert Syndrome}

Using stable HEK293T cells transfected either with wild type, Ser252Trp or Pro253Arg FGFR2 as a model Ahmed et al. ${ }^{49}$ investigated differences in intracellular response to FGF binding. Comparison of the wild type and mutant receptors revealed strikingly distinct temporal and spatial distribution of the ligand-activated receptor and the receptor-associated tyrosine phosphorylated proteins. The two mutant receptors showed altered glycosylation patterns and ligand-stimulated phosphorylation, as well as markedly upregulated downstream signaling compared to the wild type FGFR2. The prolonged engagement of the receptors expressing the extracellular mutations confers some inhibitory effect on the endocytic process. Since ligandstimulated internalisation has been reported as playing a pivotal role in signal downregulation for a number of other tyrosine kinase receptors, it is likely that the inability of the mutant receptors to undergo endocytosis may result in the apparent elevated levels of MAP kinase activity. Thus, increased FGFR2 signaling of the Ser252Trp- and Pro253Arg-mutations of FGFR2 in Apert syndrome results in signal persistence of the activated receptor complex at the cell membrane due to failure of receptor degradation in the lysosomal compartment. ${ }^{49}$

\section{Acneiform Nevus-Nevus Comedonicus}

The first case of epidermal mosaicism producing an acneiform nevus was observed in a 14-year-old boy exhibiting a somatic mutation of FGFR2 with a Ser252Trp substitution. ${ }^{66}$ Sharply demarcated linear acneiform lesions extending from the left shoulder to the antecubital fossa with comedones in virtually every follicle have been reported. ${ }^{66}$

We have observed a second case of unilateral acneiform nevus in a 15-year-old boy with unilateral segmental acne on the right chest, trunk, shoulder, arm, including the extensor surface of the forearm (Fig. 1B). ${ }^{67}$ Multiple comedones as well as inflammatory papules and pustules were found in linear or whorled skin areas reflecting the lines of Blaschko. Along with acneiform lesions, the nevus featured hypopigmentation, thinner, less pigmented terminal hairs with abnormal curled growth pattern and reduced density as compared with unaffected adjacent skin. Histological examination showed dilated plugged follicular infundibula resembling comedones, some exhibiting abscesses with foreign body reaction. Pilosebaceous follicles appeared smaller than normal and some revealed hypertrophic sebaceous glands, unusually located in the upper third of the dermis, like in Apert syndrome. Histological findings of unilateral acneiform nevus correspond to those of nevus comedonicus. Unilateral acneiform nevus is considered to represent an extensive variant of nevus comedonicus. ${ }^{68}$ The patient's general health status and that of his relatives did not show any abnormalities. Sequencing of the FGFR2 gene revealed a C to $G$ mutation in the nevus which was not present in contralateral unaffected skin and in the DNA isolated from EDTA blood. The sequence alteration detected, represents a somatic heterozygous mutation that occurred in the nevus and led to a Ser $252 \operatorname{Trp}$ amino acid change. The FGFR2 mutation of our patient is the same mutation first described in acneiform nevus of Munro and it is the same mutation reported in the majority of germline mutations in Apert syndrome. ${ }^{66,67}$

Acneiform lesions are not the only clinical features of this somatic mosaicism, as hypopigmentation and hypotrichosis are also produced. Germline as well as somatic Ser252Trp-mutations of FGFR2 result in the formation of acneiform lesions which atypically extend to the extensor surface of the forearms. Furthermore, depigmentation of hair, skin and eyes has also been described in Apert syndrome. ${ }^{69}$ Hypotrichosis in acneiform nevus can be explained by diminshed FGF7- and FGF10-signaling. Both, FGF7 and FGF10 are important for hair follicle development. FGF7-and FGF10 mRNA expression peaks at the anagen stage $\mathrm{V}^{70}$ FGF7 is also involved in skin pigmentation where it promotes melanosome transfer to keratinocytes in a FGFR2dependent process thereby regulating both the early steps of uptake and the intracellular trafficing of the phagosomes. ${ }^{71}$ Recently, acne arising strictly within a preexisting keratinocytic epidermal nevus during puberty, has been reported. ${ }^{72}$

\section{Isotretinoin Response of Acne in Apert Syndrome and Acneiform Nevus}

As shown later, retinoids downregulate FGFR2-signal transduction. ${ }^{73}$ Apert syndrome and acneiform nevus respond in a similar manner to treatment. Whereas tetracyclines were ineffective, oral isotretinoin (13cis-retinoic acid) has been shown to resolve the acneiform lesions in both, Apert syndrome and unilateral segmental acneiform nevus. ${ }^{24,28,30,67,74-77}$

In order to understand the pathogenetic role of disturbed FGF-FGFR2-signaling in Apert syndrome and acneiform nevus and its role in the pathogenesis of acne vulgaris, it has to be kept in mind, that the acne in Apert syndrome, more inflammatory lesions in acneifom nevus and acne vulgaris appear with the onset of puberty pointing to androgen dependence.

\section{Mesenchymal-epithelial FGFR2b-Signaling in Androgen-dependent Glands}

In the human, the sebaceous gland, the prostate and seminal vesicles are androgen-dependent glands. The interaction between androgen stimuli and FGF-FGFR2-signaling has been investigated in detail in the prostate because of its importance for the pathogenesis and treatment of prostatic cancer. To understand the role of FGFR2 signaling in acne, we dermatologists have to learn the lesson from urology. Comparable to the sebaceous gland, androgens are both essential and sufficient for prostate development, where they stimulate ductal outgrowths, branching morphogenesis, cellular differentiation, and secretory function. ${ }^{78,79}$ The evidence for the absolute necessity of androgen comes from the observation of absent prostate in mice or humans with complete dysfunctional ARs. ${ }^{80}$ Corresponding to the situation in the sebaceous gland, it is known that androgen-insensitive subjects who lack functional AR do not produce sebum and do not develop acne. ${ }^{10,11}$ Classic tissue recombinant experiments in the prostate showed the preferred expression of ARs in the mesenchyme. Epithelial ARs are not responsible for prostatic morphogenesis. ${ }^{81}$ It is already known for a long time that androgens induce the secretion of FGF7 in rat 
prostate stromal cells. ${ }^{82}$ Dihydrotestosterone (DHT) stimulated human prostate stromal cells to synthesize and secrete FGF7. ${ }^{83}$ FGF7 has been demonstrated to be an important mediator of mesenchymal-epithelial interaction required for androgendependent development of seminal vesicles. ${ }^{84}$ FGF10, the other important ligand of FGFR2b, functions as a mesenchymal paracrine regulator of epithelial growth in the rat prostate and seminal vesicle. ${ }^{85}$ Short-term ventral prostate and lateral prostate cultures with FGFR antagonist PD173074 and Mek inhibitor U0126 identified epithelial sonic hedgehog (Shh) and Hoxb13 upregulation by androgens to be FGF10-dependent. ${ }^{86}$ Androgens regulate prostate morphoregulatory gene expression by FGF10-dependent and FGF10-independent mechanisms. ${ }^{86}$ Importantly, recent evidence supports the view that androgens regulate the expression of prostatic morphoregulatory genes including upregulation of FGF10 expression and FGF10-signaling in the developing prostate. ${ }^{86}$ Furthermore, androgens increased FGFR2b in the ventral rat prostate, thereby increasing epithelial cell responsiveness for its ligands FGF7 and FGF10. ${ }^{86,87}$ Shh, which is an epithelial secreted morphogen, essential for prostate development, increased after testosterone stimulation as well. ${ }^{86}$ In the rat prostate, androgens regulate the expression of epithelial morphoregulatory genes of the gland, where FGF10 has been shown to be the proximate regulator of steroid action. Androgens stimulate FGF10- and FGFR2bexpression and epithelial Shh and Hoxb13 expression through an FGF10-dependent pathway. ${ }^{86}$

\section{Morphogenesis Defects of Seminal Vesicles and Prostate with Dysfunctional FGFR2b}

The importance of FGFR2 in branching morphogenesis has been presented in the mouse seminal vesicle shape (svs) mutation causing branching morphogenesis defects in the prostate and seminal vesicles. ${ }^{88}$ The svs-mutation is caused by an insertion of 491 base pairs in the $10^{\text {th }}$ intron of FGFR2 resulting in a lossof-function of FGFR2 due to changes of the pattern of FGFR2 alternative splicing. Partial loss of FGFR2b causes the svs-phenotype and was associated with downregulation by several branching morphogenesis regulators including Shh, Patched 1, Gli1 and Gli2. ${ }^{88}$ This mouse model underlines the importance of regular expression of FGFR2b for adequate branching morphogenesis of androgen-dependent seminal vesicles and prostate glands. Using conditional null FGFR2 mice embryos, a requirement for FGFR2 tyrosine kinase for prostatic branching morphogenesis, growth and acquisition of strict androgen dependency for adult tissue homeostasis could be demonstrated. ${ }^{87}$

\section{Sebaceous Gland Atrophy After Postnatal FGFR2b Deletion}

The epithelial isoform FGFR2b is essential for embryogenesis. ${ }^{37}$ FGFR2b is expressed throughout the epidermis, hair follicles and sebaceous glands. ${ }^{36}$ FGFR2b-null mice die at birth. Reciprocal intercellular signaling between epithelium and mesenchyme is a fundamental process in the induction and patterning of many organs. FGFs participate in this process instructing cells to proliferate, survive, migrate or differentiate. ${ }^{36}$ Germline knockout of the IIIb-exon of the FGFR2 gene results in mice that die at birth from multiple developmental defects, identifying FGFR2b as a critical mediator of organogenesis. ${ }^{39,89}$ Similar results were obtained by overexpressing a soluble dominant-negative version of FGFR2b. ${ }^{90}$ Studies in which FGF10 was knocked out showed that FGF10 is the key ligand for FGFR2b during development. ${ }^{91,92}$

FGFR2b has been shown to be important for postnatal skin development and hair follicle morphogenesis. ${ }^{93}$ Mouse models have been used to study FGFR2b signaling in adult skin. Mice expressing a membrane-bound, dominant-negative FGFR2b, lacking tyrosine kinase activity displayed epidermal atrophy, hair follicle abnormalities, dermal hyperthickening with severely delayed re-epithelialization of excisional wounds. ${ }^{94}$

Using Cre-Lox transgenics to delete FGFR2b postnataly in cells expressing keratin 5, it has been demonstrated that mice lacking epidermal FGFR2b survive into adulthood but displayed striking abnormalities in hair and sebaceous gland development. ${ }^{37}$ By the age of 3 months, keratin 5-FGFR2b-null mice revealed virtually absent sebaceous glands. These data confirm that FGFR2b is not only involved in sebaceous gland development but provided evidence that continued presence of FGFR2b in the skin is a necessary prerequisite for the long-term survival and homeostasis of sebocytes. ${ }^{37}$

\section{Interactions between FGFR2b and Transcription Factor p63}

Evidence accumulates that the androgen-dependent FGFFGFR2-signaling mechanisms are also operative in the sebaceous gland. The transcription factor p63 is essential for skin appendage development and induces the preferential production of the epithelial isoform FGFR2b. ${ }^{95}$ p63 regulates gene expression also at the post-transcriptional level and gives a plausible explanation for the lack of FGFR2b transcripts in $\mathrm{p} 63^{-1-}$ ectoderm. A link between p63 and FGFR2b is further supported by the similar knockout phenotypes implying that the loss of FGFR2b is likely to have a fundamental impact on the $\mathrm{p} 63^{-/-}$phenotype. ${ }^{39,89,93,96}$ Intriguingly, the observed limb defects of p63-mutants and FGFR2b-mutants are highly similar. ${ }^{39,89,97,98}$ p63 is essential for regenerative proliferation in limb, craniofacial and epithelial development, all affected tissues in Apert syndrome. ${ }^{98}$ Epidermal proliferation is grossly impaired in FGFR2b loss-of-function mutants causing a severely hypoplastic epidermis. Most important with respect to the pathogenesis of acne and Apert syndrome is the fact that FGFR2b is the major regulator of skin appendage development. FGFR2b loss-of-function mutants have reduced numbers of hair follicles. Tooth development is arrested at the bud stage and of the five pairs of mammary placodes, only one pair is formed, which however regresses later. 39,93,96 These data from animal experiments clearly show the important role and interaction of p63 and FGFR2b-signaling in organ and skin appendage development and homeostasis.

\section{Interaction Between FGFR2b and Sonic Hedgehog}

FGF $10^{-/-}$, FGFR $2 b^{-1-}$ and Shh mutant mice all exhibit cleft palate like in the Ser252Trp-FGFR2b-mutation of Apert syndrome. ${ }^{99}$ From these studies in mice it has been concluded that Shh is a downstream target of FGF10-FGFR2b signaling and that 
mesenchymally derived FGF10 regulates the epithelial expression of Shh. ${ }^{99}$ These results underline the role for FGFR2b-signaling in mammalian palate development and emphasize that coordinated mesenchymal-epithelial interactions are essential during the initial stages of palate development and require a functioning FGFR2Shh-signaling network. ${ }^{99}$

Shh-signaling is also of great importance for the regulation of sebaceous gland development. ${ }^{100}$ Interactions between $\beta$-catenin and hedgehog signaling is involved in stem cell lineage determination into lineages of the hair follicle, interfollicular epidermis and sebaceous glands. The homeostatic function of the hedgehog family is important for branching morphogenesis and limb formation. ${ }^{101}$ Within the epidermis Shh promotes proliferation of progenitors of hair lineages, whereas Indian hedgehog (Ihh) stimulates proliferation of sebocyte precursors. ${ }^{102}$ Cleft palate and syndactyly are classical features of Apert syndrome. Inborn errors of cholesterol biosynthesis with decreased cholesterol and increased cholesterol precursors cause human malformation syndromes with facial malformations, cleft palate and syndactyly like in Apert syndrome. ${ }^{103}$ Cholesterol is necessary for maturation and function of the Shh protein, which is esterified to cholesterol and palmitic acid for normal trafficking to sterol-sensing domains like Patched and membrane lipid rafts. Point mutations of the Shh downstream transcription factor Gli 3 result in Greig cephalopolysyndactyly syndrome with craniofacial abnormalities and post-axial and pre-axial polydactyly as well as syndactyly of hands and feet, clearly point to common phenotypic features observed in Apert syndrome. ${ }^{104}$ This phenotypical overlap between Apert syndrome and Greig syndrome implies that defects within the FGFR2Shh-Gli signaling pathway can result in similar developmental defects.

Studies using transgenic mice revealed that inhibition of the Shh-pathway suppressed sebaceous gland development, whereas Shh-pathway activation led to a striking increase both in size and number of sebaceous glands. ${ }^{100} \mathrm{Shh}$ is produced and secreted by developing hair follicle keratinocytes and activates signaling both in the follicular epithelium and mesenchyme. ${ }^{105,106}$ Shh acts on target cells by inhibiting the function of its receptor Patched, which normally represses the signal transducer Smoothened (Smo). ${ }^{107}$ Gli proteins mediate transcriptional responses to hedgehog family members. ${ }^{108,109}$ When Shh-mutant skin was allowed to mature on immunodeficient hosts it exhibited a selective deficiency of sebaceous glands. ${ }^{110,111}$ Stimulation of the Shh-pathway in Smo-expressing transgenic mice resulted in increased expression of the sebocyte markers Scd3 and melanocortin-5 receptor (MC5R). ${ }^{112}$ MC5R is an important marker of human sebocyte differentiation. ${ }^{12,113}$ In human sebocytes MC5R was only detectable at the onset of differentiation and in fully differentiated cells displaying prominent lipid granules. ${ }^{112,113}$ The functional link between MC5R and sebogenesis has been shown in MC5Rdeficient mice in which lack of MC5R resulted in downregulation of sebaceous lipids. ${ }^{114}$ The importance of centrally produced $\alpha$-MSH in the regulation of sebaceous lipids has been demonstrated. ${ }^{115,116}$ Ablation of the neurointermediate lobe of the pituitary, the source of circulating $\alpha-\mathrm{MSH}$, decreased sebaceous lipid production. In hypophysectomized and castrated rats the reduction of sebaceous lipids was fully restored by concomitant administration of $\alpha$-MSH and testosterone. ${ }^{116}$ In a primary human sebocyte culture system it has been reported that $\alpha-\mathrm{MSH}$ can stimulate sebocyte differentiation, sebaceous lipid production and expression of MC5R. 117,118

Thus, evidence is provided demonstrating that $\alpha-\mathrm{MSH}$ signaling via MC5R act on a common pathway with androgen-dependent expression of MC5R by induction of the signaling cascade via androgen $\rightarrow$ FGF7/FGF10 $\rightarrow$ FGFR2b $\rightarrow$ Shh $\rightarrow$ Gli $\rightarrow$ MC5Rexpression. MC5R is a crucial target gene of Shh-signaling. Moreover, the Shh-pathway is likely to play a role in postnatal function of sebaceous glands. ${ }^{100}$ Intriguingly, retinoids which are known to inhibit sebocyte differentiation and downregulate FGFR2b-signaling have been shown to reduce Gli transcriptional activity in cultured keratinocytes. ${ }^{119-121}$ This could lead to retinoid-induced downregulation of MC5R expression and lipogenesis.

In human keratinocytes epidermal growth factor receptor (EGFR) signaling modulates Shh-Gli target gene expression. ${ }^{122}$ EGFR signaling is essential for Gli-induced cell cycle progression in human keratinocytes and modulates Gli-target gene profiles which play an important role in hair follicle outer root sheath specification and hair growth. ${ }^{122}$ The biological effect of hedgehog/Gli signaling can be triggered by EGFs and FGFs. ${ }^{123-127}$ Hedgehog/ Gli signaling requires the activation of PI3K/Akt and Mek/Erk, which are activated by FGFR2b ligand binding. ${ }^{128,129}$

From this context it becomes apparent that androgen-dependent mesenchymally expressed FGF7 and FGF10 signal via epithelially expressed FGFR2b resulting in downstream upregulation of Shh and Gli leading to final expression of MC5R for terminal sebocyte differentiation and lipogenesis. In analogy to the androgen-dependent prostate gland, the androgen-dependent sebaceous gland is expected to be dependent on mesenchymal stimulation by its surrounding stromal cells, a fact neglected in studies with isolated sebocyte cell lines. The role of mesenchymal cells on sebaceous gland development and function has been recently appreciated by some investigators. ${ }^{100,130,131}$

\section{Cross-Talk Between FGFR2, EGFR, p63 and Lipogenesis}

$\Delta \mathrm{Np} 63 \alpha$ expression is dependent on activation of EGFR. ${ }^{132}$ $\triangle \mathrm{Np} 63 \alpha$ is a target of the PI3K-pathway downstream of EGFR. Inhibition of EGFR signaling results in a decrease of $\Delta \mathrm{Np} 63 \alpha$ expression. ${ }^{132}$ Both, EGFR and FGFR2, have a common signaling cascade leading to activation of PI3K, which explains the severe acne in Apert syndrome with FGFR2 gain-of-function mutations with increased FGFR2 downstream signaling. ${ }^{55}$ For the sebocyte, which is a specialized epithelial cell, it might be necessary, that p63 induces the FGFR2b-isoform, predominantly activating epithelial cells. ${ }^{133} \Delta$ Np63-induced expression of FGFR2b has been shown in mice thymic epithelial cells. ${ }^{134}$ Thus, there is a close interaction between EGFR activation, activation of PI3K-pathway, p63 expression and upregulation of FGFR2b.

The human sebaceous gland is a most active site in lipid biosynthesis. The major lipid classes of human sebum, as it leaves the 
sebaceous gland, are triglycerides, squalene, wax esters, cholesterol and cholesterol esters. Triglyceride biosynthesis affords the synthesis of free fatty acids. There are three major mechanisms utilized for the synthesis of fatty acids: de novo-synthesis, microsomal elongation and the mitochondrial process. The de novo-mechanism involves two enzymes, the acetyl-CoA-carboxylase and the fatty acid synthase. ${ }^{135}$ Since the major component fatty acid in human sebum is palmitic acid, it can be deduced that de novo-fatty acid synthesis by the enzyme fatty acid synthase is the major mechanism for sebaceous gland lipogenesis. ${ }^{135}$ The regulation of fatty acid synthase gene expression is intimately involved in sebum production. It fits well together, that the master transcription factor $\Delta \mathrm{Np} 63$ induces fatty acid synthase (FASN) mRNA levels, while $\Delta \mathrm{Np} 63$-silencing produces a decrease of FASN expression. ${ }^{136}$ A correlation between $\Delta \mathrm{Np} 63 \alpha$ and FASN expression in cellular proliferation could be observed. ${ }^{136}$ These interactions shed a new light on EGFR-p63-FGFR2b-mediated regulation of FASN-dependend sebaceous lipogenesis. The androgen-dependent mesenchymally-secreted FGF7 and FGF10 signals activate the epithelial FGFR2b on sebocytes thereby upregulating EGFR, the convergent point of many co-stimulatory hormones signaling through G-protein-coupled receptors. ${ }^{137}$ Comparison of EGFR, FGFR1 and IGF1R downstream signaling pathways show, that for the most part, a similar repertoire of signaling proteins are recruited and activated by these tyrosine kinase receptors. ${ }^{138,139}$ A cooperative interaction between EGFR, FGFR2b- and IGF1Rsignaling in the pilosebaceous follicle has to be expected in mesenchymal-epithelial interactions for sebaceous gland development and homeostasis in the adult tissue.

\section{Androgen-Dependent FGFR2-Signaling in Acne of Apert Syndrome}

The acne lesions of Apert syndrome are not present from birth but develop in the course of puberty and are reported to appear early in puberty, more severe and in an unusual distribution extending to the surface areas of the forearms like those we have observed in acneiform nevus. Androgens are necessary for the induction of the acneiform lesions. As plasma androgen levels and AR expression and distribution are not disturbed in Apert syndrome, the clinically appearing increased androgen-sensitivity is best explained by the gain-of-function-FGFR2-mutations which are activated by increased synthesis of FGFs raising by androgen stimulation during puberty. The resolution of severe acne in a woman with Apert syndrome by anti-androgenic treatment points to the underlying androgen dependence of FGFR2-signal transduction. ${ }^{140}$

\section{Ser252Trp-FGFR2-Mutation and Comedogenesis}

Unilateral acneiform nevus is regarded as an extensive variant of nevus comedonicus. ${ }^{141}$ Nevus comedonicus appears clinically as linear groups of open comedones presenting confluent clusters of dilated follicular orifices plugged with keratin. About $50 \%$ of cases are evident at birth, with the other 50\% developing before the age of 10 years. Inflammatory lesions like in our case are seen during puberty. ${ }^{142}$ Characteristic histological features of nevus comedonicus closely resemble our case of unilateral acneiform nevus. Nevus comedonicus has been considered to be an organoid epidermal nevus involving the hair follicle. ${ }^{68} \mathrm{~A}$ focal clonal defect in growth regulation of infundibular keratinocytes has been postulated. ${ }^{143}$ FGFR2b is expressed mainly in the suprabasal spinous layer of epidermis and plays a crucial role in controlling epithelial proliferation and differentiation. ${ }^{35}$ Activation of FGFR2b induces differentiation-specific keratin expression in the suprabasal layers. ${ }^{35}$ Increased expression of fillagrin, a marker of terminal differentiation of epidermis, has been detected in both superficial and intermediate cells in closed comedones of nevus comedonicus. ${ }^{68}$ Elevated levels of IL- $1 \alpha$-like bioactivity has been detected in the majority of open comedones in acne vulgaris. ${ }^{12}$ Keratinocytes synthesize and secrete various cytokines including IL-1. ${ }^{144}$ The stimulation of human sebaceous infundibula in culture with IL-1 $\alpha$ resulted in morphological changes similar to hypercornification, hyperkeratinisation and reduced desquamation of comedo formation. ${ }^{13}$ Based on increased labelling of the comedonal wall with tritiated thymidine, Plewig et al. ${ }^{145}$ proposed that comedogenesis in acne vulgaris resulted from hyperproliferation and retention hyperkeratosis. Hyperproliferation and hypercornification of the follicular wall could be blocked by the addition of IL-1 receptor antagonist. ${ }^{13}$ These observations underline the importance of IL-1 $\alpha$ in comedogenesis. Thus, the question arises whether the Ser252Trp-FGFR2-mutation is associated with increased IL-1 $\alpha$ signaling. Indeed, a threefold increased expression of IL-1 $\alpha$ was observed in Ser252Trp-FGFR2 mutated human osteoblasts of Apert syndrome. ${ }^{47}$ Osteoblasts are cells of mesenchymal origin like fibroblasts who are capable of IL-1 $\alpha$ synthesis. When investigating the proliferative activity of follicular epithelia and sebaceous glands, a significant radioactive labelling could be detected in fibroblasts surrounding the infundibular area, pointing to increased fibroblast activity. ${ }^{145}$ In fact, perifollicular fibrosis has been observed in lesions of nevus comedonicus. ${ }^{68}$ Thus, indirect evidence supports the view that the Apert mutation of FGFR2 leads to infundibular overexpression of IL- $1 \alpha$, which appears to be the driving force of comedo formation in nevus comedonicus and Apert syndrome.

\section{FGFR2b-Signaling in Acne Vulgaris}

Androgens are important for the maturation of androgendependent organs during puberty. ${ }^{146}$ The FGFR2b-signaling pathway is androgen-regulated and plays an important role in sebaceous gland development and homeostasis. Different from Apert syndrome, where FGF2 appears to be the major ligand for FGFR2b, FGF7 and FGF10 are supposed to mediate mesenchymally-derived signals to the infundibular epithelium and sebaceous glands under physiological conditions and in acne vulgaris. The following signaling pathways are predictable: With the onset of puberty increased plasma androgen levels stimulate the surrounding perifollicular stroma of sebaceous glands and its infundibum to increase the expression of FGF7 and FGF10. In a paracrine fashion, FGF7 and FGF10 bind to its epithelial receptor FGFR2b on sebocytes and follicular duct keratinocytes. FGFR2b activation leads to downstream expression 
of various target genes including the expression IL- $1 \alpha$ and Shh. Shh-Ptch-Smo-Gli-signaling induces terminal differentiation of sebocytes, upregulation of MC5R and MC5R-dependent lipogenesis. Androgen-mediated upregulation of EGFR augments the FGFR2b-effect by the increasing G-protein-coupled receptormediated EGFR-transactivation. FGF7-binding to FGFR2b has been shown to induce TGF $\alpha$ and EGFR-upregulation in cultured keratinocytes. ${ }^{147}$ Activated FGFR2b and EGFR work in cooperative fashion, using overlapping downstream signaling cascades (Fig. 3). ${ }^{138}$ FGFR2b-mediated upregulation of IL-1 $\alpha$ is involved in hyperproliferation of infundibular keratinocytes and comedo formation. In acne vulgaris androgen-induced overstimulation of the FGF7/10-FGFR2b-IL-1 $\alpha$-pathway might induce hyperproliferation and activation of infundibular keratinocytes and sebocytes.

\section{Interleukin-1 $\alpha$ Network in Keratinocytes}

IL-1 $\alpha$ has been demonstrated in vitro to cause comedonal features in isolated pilosebaceous units. ${ }^{13,148}$ In vivo, comedones contain enough IL- $1 \alpha$ activity to initiate a non-specific inflammatory response if released into the dermis. ${ }^{12}$ Increased IL- $1 \alpha$ immunoreactivity was found in the follicle wall of pilosebaceous units from uninvolved skin and comedones. ${ }^{149}$ Immunohistochemical studies of earliest subclinical acne lesions demonstrated an increase of IL-1 $\alpha$ labelling in all layers of interfollicular and perifollicular epidermis and down the follicle wall of uninvolved skin of acne patients compared to controls. ${ }^{150}$ Down the follicular wall only labelling in the infrainfundibular basal cells increased, whereas labelling in the suprabasal layers of the infrainfundibulum and all layers of the acroinfundibulum did not differ in intensity in uninvolved skin of acne patients and early inflamed lesions. ${ }^{150}$

Within the dermis IL1- $\alpha$ labelling presented a discrete cellassociated immunoreactivity with the majority of positive cells located perifollicularly, whereas in normal skin only a small number of dermal cells expressed IL-1 $\alpha .{ }^{150}$ However, around follicles of uninvolved skin of acne patients, dermal IL- $1 \alpha$ was three-fold elevated compared to normal skin. ${ }^{150}$ Increased IL-1 $\alpha$ activity around uninvolved follicles of acne patients prior to that of hyperproliferation points to the importance of IL- $1 \alpha$ as the initiating factor for comedogenesis. IL-1 $\alpha$ is constitutively expressed by keratinocytes, which also synthesize IL-1 receptor antagonist (IL-ra), a specific inhibitor of IL-1 activity. Keratinocytes store prodigious quantities of preformed IL- $1 \alpha$ and synthesize IL-1 $\beta$, IL1-ra and IL-1 receptors, which are controlled by counterregulation of IL- $1 \alpha$ and IL-ra. ${ }^{151}$ Increases in IL- $1 \alpha$ and IL-1 ra were observed as normal keratinocytes differentiated from basal stem cells into transient amplifying cells. ${ }^{152}$ Within the basal stem cell population of normal keratinocytes, the IL- $1 \alpha$ and IL-1ra levels increased between $G_{0} / G_{1}$ - and S-phase of the cell cycle. The IL- $1 \alpha$ - and IL1-ra of normal transient amplifying cells increased throughout the cell cycle. ${ }^{152}$

\section{Interleukin-1 $\alpha$ and Follicular Keratinocyte Activation}

Epidermal keratinocytes have two alternative pathways open to them: differentiation and activation. ${ }^{153}$ Activated keratinocytes are hyperproliferative, produce paracrine and autocrine signals, alert fibroblasts, endothelial cells, T-cells and neighboring keratinocytes change their cytoskeleton. ${ }^{153}$ Characteristically, activated keratinocytes express keratin proteins K6, K16 and K17. ${ }^{153}$ The first signal initiating the keratinocyte activation cycle is released IL-1 $\alpha .{ }^{153}$ Keratins $\mathrm{K} 6$ and $\mathrm{K} 16$ are markers of the activated state. Expression of K6, K16 and K17 has been detected with cytokeratin-specific antibodies in infundibular epithelial cells, sebaceous duct cells and differentiated sebaceous cells of normal controls and acne patients. ${ }^{154}$ In comparison to controls, acne patients exhibited an increased filaggrin expression. ${ }^{155}$ In the comedone wall an increased suprabasal expression of $\mathrm{K} 6$ and K16, and panepithelial expression of K17 could be demonstrated. ${ }^{155}$ It is noteworthy that the expression of FGFR2b, IL1 receptor type I and of keratins K6, K16 and K17 co-localize in suprabasal cells pointing to their close spatial and functional relations for the induction of activated keratinocytes. ${ }^{35,156-158}$

Aberrant $\alpha_{2}$ - and $\alpha_{3}$-integrin expression around comedones and uninvolved pilosebaceous follicles from acne patients further support the activated keratinocyte status of follicular keratinocytes in acne vulgaris. ${ }^{159}$ It is most likely that increased IL- $1 \alpha$ activity has initiated the upregulation of vascular adhesion molecules, ICAM-1, E-selectin and VCAM-1 and the cellular migration of $\mathrm{CD}^{+}{ }^{+}$-T-cells and macrophages found in uninvolved and early inflammatory lesions of acne patients. ${ }^{150}$ It is conceivable that androgen-dependent FGFR2-mediated release of IL-1 $\alpha$ by infrainfundibular keratinocytes is the primary stimulus leading to comedogenesis, a state of secretory keratinocyte activation inducing the perifollicular infiltration by T-cells and macrophages. A further link between IL- $1 \alpha$ and initiation of the immune response is the fact that, activated IL-1 receptor associated kinases (IRAKs) are critically involved in the IL-1 receptor/Toll-like receptor-mediated signal transduction processes that regulate cellular innate and adaptive immune responses. ${ }^{160}$

\section{The Double Paracrine Pathway of Keratinocyte Growth Regulation}

Mesenchymal-epithelial interactions are essential in regulating epidermal tissue homeostasis. ${ }^{161}$ This interplay is largely mediated by soluble factors produced by dermal cells acting as paracrine regulators of keratinocyte growth and differentiation. ${ }^{162,163}$ Thus, balanced keratinocyte proliferation and differentiation strictly depend on dermal support. In three-dimensional organotypic co-culture models it has been demonstrated that keratinocytederived IL-1 $\alpha$ induced the expression of FGF7 in co-cultured fibroblasts. ${ }^{164}$ These experiments confirmed the existence of a double paracrine signaling pathway between keratinocytes and fibroblasts involving IL-1 and FGF7 in keratinocyte growth regulation. ${ }^{164}$ Keratinocytes in organotypic cultures not only upregulate IL- $1 \alpha$ and IL-1 $\beta$, but also FGFR2b. ${ }^{164}$ Similarly, fibroblasts co-cultured in a collagen gel exhibit enhanced expression not only of FGF7 but also of IL-1 receptor type I. ${ }^{164}$ IL-1 is a rate limiting, initiating step of the double paracrine loop of mesenchymal-epidermal interaction. A specific antagonistic control by the transcription factors c-Jun and JunB of IL-1-regulated gene 
expression of FGF7 and GM-CSF for keratinocyte proliferation and differentiation has been identified. ${ }^{165}$

\section{Interleukin-1 $\alpha$ and Sebocyte Activation}

Sebocytes like keratinocytes are derived from a common precursor stem cell. ${ }^{102}$ They are able to produce IL-1 $\alpha .{ }^{166}$ All layers of glandular and ductal cells of sebaceous glands were immunoreactive for both IL- $1 \alpha$ and IL-1 $\beta .{ }^{167}$ In sebaceous cells of seborrheic skin immunostaining with an antibody specific for keratins $\mathrm{K} 7$, K16, K17 and K19 increased from undifferentiated to mature cells. ${ }^{154}$ Increased expression of K17 could be detected in sebaceous glands and sebaceous ducts of uninvolved skin of acne patients, although sebaceous glands showed heterogeneity in keratin expression, with some lobules expressing keratins K1, K5, K7, K10, K14 and K17. ${ }^{155}$ Inhibiton of the ectopeptidases dipeptidyl peptidase IV and aminopeptidase $\mathrm{N}$ on human sebocytes induced IL-1 ra and slightly decreased total neutral lipid production, suppressed proliferation of sebocytes and enhanced terminal differentiation. ${ }^{168}$ Furthermore, ectopetidase inhibitors suppressed proliferation and IL-2 production of Propionibacterium acnes-stimulated T-cells ex vivo and enhanced the expression of transforming growth factor $-\beta_{1}$ $\left(\mathrm{TGF} \beta_{1}\right) .{ }^{168} \mathrm{TGF} \beta$ is the important de-activating signal that promotes reversal of activated keratinocytes back to the basal phenotype inducing expression of keratins K5 and K14. ${ }^{153}$ Suppression of DNA synthesis of viable SZ95 sebocytes after incubation with ectopeptidase inhibitors was comparable to that of isotretinoin, which significantly suppressed SZ95 proliferation at $10^{-6}$ and $10^{-5} \mathrm{M}$ concentrations. ${ }^{168} \mathrm{It}$ is tempting to speculate that isotretinoin induces TGF $\beta$ thereby terminating the keratinocyte/sebocyte activation cycle in acne vulgaris. Indeed, TGF $\beta_{2}$ has been shown to be selectively induced by retinoic acid in keratinocytes. ${ }^{169}$ Retinoic acid treatment of pancreatic cancer cells induced a TGF $\beta_{2}$-dependent growth inhibition in a p53-independent and partially $\mathrm{p} 21^{\mathrm{wafl}}$-dependent pathway. ${ }^{170}$ In these cell lines all isoforms of retinoic acid (9-cis, 13-cis and all-trans) were equipotent in inducing growth inhibition. ${ }^{171}$ All-trans-retinoic acid induces hair follicle regression to catagen by upregulation of TGF $\beta_{2}$ in the dermal papilla. ${ }^{172}$ Ligand binding to TGF $\beta$ receptor has been shown to induce the FGFR antagonist sprouty which suppresses downstream FGFR-signaling. ${ }^{73,173}$ Future studies should clarify, whether the induction of $\mathrm{TGF} \beta_{1}$ or $\mathrm{TGF} \beta_{2}$ in the pilosebaceous follicle by retinoids is the primary de-activating signal of activated keratinocytes and sebocytes by sprouty-mediated downregulation of FGFR2b-signaling in acne vulgaris.

\section{Interaction Between FGFR2b- and IGFIR-Signaling in Acne}

Hormonal changes during puberty involve an increase in serum levels of growth hormone $(\mathrm{GH})$, insulin and insulin-like growth factor-1 (IGF-1) associated with hormonal changes in adrenal and gonadal androgen metabolism. The key regulator of growth, IGF-1 (somatomedin C), rises during puberty by the action of increased GH secretion and correlates well with the clinical course of acne. ${ }^{174}$ In acne patients associations between serum levels of IGF-1, dehydroepiandrosterone sulfate, dihydrotestosterone, acne lesion counts and facial sebum secretion rate have been reported. ${ }^{175-177}$ IGF-1 stimulates $5 \alpha$-reductase, adrenal and gonadal androgen synthesis, AR signal transduction, sebocyte proliferation and lipogenesis. ${ }^{178-184}$ Milk consumption results in a significant increase in IGF-1 serum level and exerts strong insulinotropic effects comparable to high glycaemic food. ${ }^{185,186}$ Insulin induces hepatic IGF-1 secretion, and both hormones amplify the stimulatory effect of GH on sebocytes and augment mitogenic downstream signaling pathways of insulin receptors, IGF-1 receptor and FGFR2b (Fig. 3). ${ }^{187}$ Acne is proposed to be an IGF-1-mediated disease, aggravated by diets high in milk protein and glycaemic index. ${ }^{187-189}$

IGF1R primarily regulates cellular proliferation and to a lesser extend differentiation, whereas FGFR2b is predominantly involved in the regulation of cellular differentiation. ${ }^{119,190}$ Comedogenesis is considered to be a process of increased keratinocyte proliferation as well as exaggerated keratinocyte differentiation (hyperkeratinisation). ${ }^{145}$ From studies on human keratinocyte cell culture models it has been concluded that the normalizing activity of retinoids on diseases with hyperkeratinization, such as acne, is mediated by modulation of differentiation rather than cell growth. ${ }^{191}$ Both tyrosine kinase receptors, the IGF1R expressed on basal cells, and FGFR2b expressed on suprabasal cells, regulate canonical cellular pathways involved in proliferation and differentiation of sebocytes and keratinocytes. Both, FGFR2b and IGF1R activate MAPKand PI3K/Akt signalling pathways. ${ }^{138,192}$ Substantial qualitative overlap in the recruitment profiles of IGF1R, FGFR1 and EGFR has recently been demonstrated. ${ }^{139}$ Figure 3 shows that IGF1R and FGFR2b share common downstream signal transduction pathways which involve the action of androgens, GH, IGF-1 and FGFs. IGFR1 signaling upregulates androgen synthesis, the conversion of less potent to more potent androgens and AR activation. The androgen-dependent expression of FGF7 and FGF10, the ligands of FGFR2b, are increased by IGF-1-mediated AR signaling. In this regard IGF1R-signaling has co-stimulatory effects on FGFR2b signal transduction.

IGF-1 not only activates androgen synthesis, metabolism and AR-signaling, but is itself induced by androgen-mediated signaling. Stimulation of the rat ventral prostate with DHT induced the expression of 234 androgen-dependent gene transcripts. Two of the most significantly expressed androgen-dependent genes were the hormone IGF-1 and the transcription factor SREBP-1c. ${ }^{193}$ It has recently been shown that DHT and testosterone each increased IGF-1 (seven-fold) and decreased IGFBP-3 (two-fold) mRNA expression and protein secretion in a dose- and timedependent manner in human prostatic stromal cells. ${ }^{194}$

Thus, androgen-dependent signal transduction and the adrenal and gonadal androgen synthesis are dependent on IGF-1. In androgen-dependent glands like the prostate, seminal vesicle and most likely the sebaceous gland, androgens induce the mesenchymal expression of FGF7 and FGF10 thereby activating FGFR2b-signaling. Moreover, androgens induce stromal IGF-1 secretion, thereby augmenting IGF1R-signal transduction which substantially overlaps with downstream FGFR2b-signaling. 
Table 1 Tyrosine kinase-dependent regulatory effects of growth factors important in PI3K activation, epithelial cell proliferation, differentiation and lipogenesis

\begin{tabular}{|c|c|c|}
\hline Receptor ligand & Tyrosine kinase receptor & PI3K-dependent effects \\
\hline \multirow[t]{2}{*}{ FGF7, FGF10 } & FGFR2b & $\begin{array}{l}\text { - keratinocyte proliferation and differentiation, } \\
\text { upregulation of Shh, Gli and MC5R, lipogenesis, } \\
\text { - upregulation of SREBP-1, lipogenesis } \\
\text { increased expression of IL-1 } \alpha \text {, initiation of inflammation, } \\
\text { induction of the keratinocyte activation cycle, } \\
\text { - upregulation of PI3K, MAPK, PKC } \\
\text { - increased expression of IL-1 } \alpha\end{array}$ \\
\hline & $\begin{array}{l}\text { Ser252Trp- and } \\
\text { Pro253Arg-gain-of-function } \\
\text { FGFR2 mutations }\end{array}$ & \\
\hline IGF-1, insulin & IGFIR & $\begin{array}{c}\text { - phosphoryation of Foxol and activation of AR, increase in AR-mediated signal transduction, } \\
\text { - upregulation of SREBP-1, sebaceous lipogenesis }\end{array}$ \\
\hline EGF & EGFR & - upregulation of Shh, Gli, p63 \\
\hline other EGFR ligands & & $\begin{array}{l}\text { - p63-mediated expression of FGFR2b-splice variant of FGFR2, } \\
\text { - p63-induced expression of FASN (lipogenesis) }\end{array}$ \\
\hline
\end{tabular}

\section{FGFR2b and IGFIR-mediated Activation of PI3K/Akt Dependent Lipogenesis}

Both, FGFR2b and IGF1R tyrosine kinase result in activation of the PI3K/Akt pathway which stimulates increased expression of sterol response element binding protein-1 (SREBP-1), the master regulator of lipogenesis which controls cellular lipid homeostasis and maintenance of membrane sterol levels. ${ }^{195}$ Both, FGF7, the ligand of FGFR2b, and IGF-1, the ligand of IGF1R, have been shown to induce lipogenic genes. In H292 epithelial cells, FGF7 induces proliferation and lipogenic genes through a PI3K and JNK/ SREBP-1 pathway. ${ }^{196}$ In 3-day sebaceous gland organ cultures, IGF-1 induced ${ }^{14} \mathrm{C}$-acetate uptake in a dose-dependent manner indicative for activated lipogenesis. ${ }^{183}$ In human SEB-1 sebocytes, IGF-1 has been shown to activate PI3K/Akt and MAPK/ERK-signal transduction pathways. ${ }^{197}$ Activation of the PI3K/Akt-pathway by IGF-1 induced SREBP-1 mRNA and -protein and increased sebaceous lipogenesis. ${ }^{197}$ Addition of a specific PI3K-inhibitor (LY294002) resulted in the downregulation of transcription, translation and processing of SREBP-1 and sebaceous lipogenesis. ${ }^{197}$ SREBP-1 is upregulated by androgens in the hamster ear sebaceous model. ${ }^{198}$ Thus, the co-stimulatory effects of androgens, FGF7 and IGF-1 on SREBP-1 induction and lipogenesis can be well explained by the androgen-dependent stromal upregulation of FGF7, FGF10 and IGF-1 in androgen-dependent glands which all result in convergent signaling by activation of FGFR2b- and IGF1R downstream PI3K/Akt-activation (Table 1). ${ }^{82-85,194}$

\section{Attenuation of FGFR2b-Signal Transduction by Anti-Acne Agents}

If FGFR2b-mediated signal transduction plays an essential role in the pathogenesis of acne, the mode of action of currently used anti-acne agents should interfere with FGFR2b signaling.
Indeed, all anti-acne agents may exert their therapeutic action by attenuation of increased FGFR2b-signal transduction in acne. ${ }^{73}$ Anti-androgens suppress stromal androgen-dependent FGF-ligand expression, ${ }^{86,87}$ benzoyl peroxide induces FGFR2b downregulation by lysosomal receptor degradation, ${ }^{51}$ azelaic acid inhibits mitochondrial ATP formation required for receptor tyrosine kinase and further downstream kinase phosphorylation steps, ${ }^{199}$ tetracyclines inhibit the expression and activity of FGFR2binduced downstream matrix metalloproteinases, ${ }^{200}$ and retinoids attenuate the FGFR2 pathway at several regulatory levels of the signal transduction cascade critical for cell cycle control, cell proliferation, differentiation and lipogenesis. All-trans retinoic acid (at-RA)-induced sprouty acts as an important FGFR antagonist. Sprouty 2 plays a key role in negatively modulating FGFR signaling pathways. ${ }^{173,201}$ Tyrosine phosphorylated sprouty creates a decoy site that binds the docking molecule Grb2 and prevents SOS from activating Ras. ${ }^{48}$ atRA-induced sprouty antagonizes FGF signaling by sequestering Grb2, preventing its binding to FRS2. Sprouty2 inhibits the Ras/MAP kinase pathway by inhibiting the activation of Raf. $^{202}$ There are further retinoid-dependent inhibitory mechanisms for the attenuation of FGF signaling involving the dual-specificity MAP kinase phosphatases MKP1 and MKP3 which de-phosphorylate activated ERK1/ERK2. ${ }^{48}$ Erythromycin, a P-450 inhibitor, may interfere with FGFR2 signaling as well by its inhibitory effect on retinoid catabolism which may favor retinoid-mediated upregulation of the FGFR antagonist sprouty. ${ }^{73,203}$

\section{Overlap of Ectopeptidase- and FGFR2-mediated Signaling}

The signal Ras/Raf/MAPKK/MAPK transduction pathway is activated in almost all growth factors. ${ }^{204}$ It should be noticed that activation of MAPK pathways downstream of ectopeptidases converge with signal transduction pathways of other growth factor 
receptors like FGFR2. ${ }^{204}$ The activation status of cells of the pilosebaceous unit might be either downregulated by increasing IL-1 ra and TGF $\beta$ by ectopeptidase inhibitors or decreasing IL-1 $\alpha$ by inhibition of PKC $\alpha$, PI3K/Akt and/or MAPK. 47,171 New options of therapeutic intervention in the treatment of acne should consider selective inhibition of FGFR2b- and IGF1R tyrosine kinase activity, the PI3K-Akt pathway, and ectopeptidases in acne-prone skin. ${ }^{190,197}$

\section{Retinoid Embryopathy Caused by Suppression of Fetal FGFR2-Signaling?}

FGFs are signaling molecules that mediate a variety of cellular responses during embryonic development and in the adult organism. During craniofacial development signaling through FGFR2 is important as mutations in FGFR2 or its ligands affect calvaria, tooth and palate development. ${ }^{31}$ Embryopathy associated with the mother's exposure to $13 \mathrm{cRA}$ during the first trimester of pregnancy includes craniofacial, cardiac, thymic and central nervous system malformations. ${ }^{205}$ The human Accutane dysmorphic syndrome includes rudimentary external ears, absent or imperforate auditory canals, a triangular microcephalic skull, cleft palate, depressed midface and anomalies of the brain, jaw, heart and limb defects. ${ }^{206}$ The suppression of FGFR-signaling during embryonic development explains the teratogenic effect of retinoids. Retinoid embryopathy is often associated with the formation of cleft palate. ${ }^{207}$ Intriguingly, disruption of the FGF10/FGFR2bcoordinated epithelial-mesenchymal interactions has been shown to cause cleft palate. ${ }^{99}$ In the mouse model 13cRA induced limb defects and median cleft lips. ${ }^{208}$ By abrogating signal transduction of FGFR1, FGFR2 and FGFR3 it has been concluded that FGFR-mediated signaling is essential for normal mammalian palate development. ${ }^{209}$ Knock out of FGFR2b in a mouse model resulted in the cleft palate phenotype. FGFR2b null mice exhibit agenesis or dysgenesis of various organs, which undergo budding and branching morphogenesis. FGF10 acts a major ligand for FGFR2b in mouse multi-organ development. ${ }^{210}$ FGFR2 is required for limb outgrowth and lung branching morpohgenesis. $^{211,212}$ Loss-of-function mutation of FGFR2 or FGF10 leads to lacrimo-auriculo-dental-digital (LADD) syndrome. ${ }^{213}$ Thus, retinoid-mediated suppression of FGFR2 signaling during a sensitive phase of fetal development would explain the teratogenic effects of retinoids, a further support in favor of the involvement of the FGFR2 signaling pathway. These observations allow the conclusion that retinoid teratogenicity is a result of intrauterine fetal FGFR2-inhibion disturbing crucial events of FGFR2-dependent morphogenesis. The new concept of FGFR2-dependent retinoid teratogenicity is an excellent agreement with the role FGFR2 as a most important mesenchymal-epithelial signaling system for morphogenesis of many organ systems including the development and homeostasis of the pilosebaceous follicle.

\section{Conclusion}

Apert syndrome and unilateral segmental acneiform nevus with FGFR2 gain-of-function mutations are associated with increased susceptibility for the development of acne. These genetic models of nature showed us the right way to understand reciprocal mesenchymal-epithelial signaling for pilosebaceous gland development and homeostasis. Now, we understand that the sebaceous gland like other androgen-dependent glands maintains dermal-epithelial interaction by release of stromal FGF7 and FGF10. FGF expression has been shown to be dependent on stromal androgens, whereas keratinocyte-derived IL- $1 \alpha$ is a further epithelial stimulus upregulating the expression of FGF7 in a double paracrine mode. The importance of FGFR2b-derived signals for the homeostasis of infundibular keratinocytes and sebocytes has been demonstrated by FGFR2b deletion and knockout mouse models. The FGFR2b-signal transduction pathway is the connecting piece for a variety of already well known pathogenetic factors involved in pilosebaceous homeostasis like androgens, IGF-1, IL-1 $\alpha$, p63, Shh, Gli, MC5R, EGFR, IGF1R, PI3K/ Akt, SREBP-1 and sebaceous lipogenesis (Fig. 3). Dermal cells in the vicinity of sebaceous glands appear to be of physiological importance for proper growth factor signaling, a critical requirement overlooked when acne research had focused only on isolated epithelial cell lines. Clinical observation, animal experiments, and experience in developmental biology support the unifying concept of an exaggerated androgen-dependent mesenchymalepithelial interaction to be of key importance for increased cell proliferation, activation and differentiation of infundibular keratinocytes and sebocytes in acne vulgaris. The physiologic role of the FGFR2b tyrosine kinase receptor gets further support by the concept that all anti-acne agents may exert their therapeutic effects by downregulation of increased FGFR2b signal transduction. Moreover, accidental downregulation of FGFR2 signal transduction with isotretinoin during early pregnancy may explain retinoid embryotoxicity. These new insights in the regulatory network of FGFR2b-signaling in acne offer new therapeutic strategies which should focus on downregulation of increased signaling through tyrosine kinase receptors like FGFR2b and IGF1R. Selective local pharmacological inhibition of these interacting tyrosine kinase receptors and their overlapping downstream targets like PI3K/ Akt might be very promising for the control of acne. Thus, the presented concept supports the viewpoint of Lowell A. Goldsmith who stated: "Les jeux sont fait: Put your bets on FGFR2." 214

References

1. Kligman AM, Shelly WB. An investigation into the biology of the sebaceous gland. J Invest Dermatol 1958; 30:99-125.

2. Plewig G. Acne vulgaris: proliferative cells in sebaceous glands. Br J Dermatol 1974; 90:623-30.

3. Downing DT, Strauss JS. On the mechanism of sebaceous secretion. Arch Dermatol Res 1982; 272:343-9.

4. Pochi PE, Strauss JS. Sebaceous gland response in man to the administration of testosterone, delta-4-androstendione and dehydroisoandrosterone. J Invest Dermatol 1969; 52:32-6.

5. Thiboutot D, Knaggs H, Gilliland K, Lin G. Activity of 5-alpha-reductase and 17-betahydroxysteroid dehydrogenase in the infrainfundibulum of subjects with and without Acne vulgaris. Dermatology 1998; 196:38-42.

6. Marynick SP, Chakmakjian ZH, McCaffree DL, Herndon JH Jr. Androgen excess in cystic acne. N Engl J Med 1983; 308:981-6.

7. Melnik B, Jansen T, Grabbe S. Abuse of anabolic-androgenic steroids and bodybuilding acne: an underestimated health problem. J Dtsch Dermatol Ges 2007; 5:110-7.

8. Schmidt JB, Spona J, Huber J. Androgen receptor in hirsutism and acne. Gynecol Obstet Invest 1986; 22:206-11. 
9. Thiboutot D, Harris G, Iles V, Cimis G, Gilliland K, Hagari S. Activity of the type 1 alpha-reductase exhibits regional differences in isolated sebaceous glands and whole skin. J Invest Dermatol 1995; 105:209-14.

10. Zouboulis CC. Treatment of acne with antiandrogens-an evidence-based review. J Dtsch Dermatol Ges 2003; 1:535-46.

11. Imperato-McGinley J, Gautier T, Cai LQ, Yee B, Epstein J, Pochi P. The androgen control of sebum production. Studies of subjects with dihydrotestosterone deficiency and complete androgen insensitivity. J Clin Endocrinol Metab 1993; 76:524-8.

12. Ingham E, Eady EA, Goodwin CE, Cove JH, Cunliffe WJ. Proinflammatory levels of interleukin 1alpha-like bioactivity are present in the majority of open comedones in Acne vulgaris. J Invest Dermatol 1992; 98:895-901.

13. Guy R, Green MR, Kealey T. Modeling acne in vitro. J Invest Dermatol 1996; 106:176-82.

14. Apert E. De là acrocéphalosyndactylie. Bull Soc Med Hop (Paris) 1906; 23:1310-30.

15. Muencke M, Wilkie AOM. Craniosynostosis syndromes. In: The Metabolic \& Molecular Bases of Inherited Disease (Scriver CR, Beaudet AL, Sly WS, et al. eds) McGraw-Hill, New York St. Louis San Francisco, eighth ed., vol 4, chapter 2001; 245:6117-46.

16. Ornitz DM, Marie PJ. FGF signaling pathways in endochondral and intermembraneous bone development and human genetic disease. Genes Develop 2002; 16:1446-65.

17. Freiman A, Tessler O, Barankin B. Apert syndrome. Int J Dermatol 2006; 45:1341-3.

18. Solomon LM, Fretzin DF, Pruzansky S. Pilosebaceous abnormalities in Apert's syndrome. Arch Dermatol 1970; 102:381-5.

19. Solomon L, Cohen M, Pruzansky S. Pilosebaceous abnormalities in Apert type acrocephalosyndactyly. Birth Defects 1971; 7:193-5.

20. McNaughton PZ, Rodman OG. Apert's syndrome. Cutis 1980; 25:538-40.

21. Steffen C. Acneiform eruption in Apert's syndrome. Acrocephalosyndactyly. Arch Dermatol 1982; 118:206-8.

22. Steffen C. The acneiform eruption of Apert's syndrome is not Acne vulgaris. Am J Dermatopathol 1984; 6:213-20.

23. Robinson D, Wilms NA. Successful treatment of the acne of Apert's syndrome with isotretinoin. J Am Acad Dermatol 1989; 21:315-6.

24. Parker TL, Roth JG, Esterly NB. Isotretinoin for acne in Apert syndrome. Pediatr Dermatol 1992; 9:298-300.

25. Cohn MS, Mahon MJ. Apert's syndrome (acrocephalosyndactyly) in a patient with hyperhidrosis. Cutis 1993; 52:205-8.

26. Cohen MM, Kreiborg S. Cutaneous manifestations of Apert syndrome. Am J Med Genet 1995; 58:94-6.

27. Henderson CA, Knaggs H, Clark A, Highet AS, Cunliffe WJ. Apert's syndrome and androgen receptor staining of the basal cells of sebaceous glands. Br J Dermatol 1995; 132:139-43

28. Downs AM, Codon CA, Tan R. Isotretinoin therapy for antibiotic-refractory acne in Apert's syndrome. Clin Exp Dermatol 1999; 24:461-3.

29. Linss G. Acrocephalosyndactyly I (Apert syndrome) Hautarzt 2000; 51:685-7.

30. Campanati A, Marconi B, Penna L, Paolinelli M, Offidani A. Pronounced and early acne in Apert's syndrome: a case successfully treated with oral isotretinoin. Eur J Dermatol 2002; 12:496-8.

31. Veistinen L, Aberg T, Rice DPC. Convergent signaling through Fgfr2 regulates divergent craniofacial morphogenesis. J Exp Zool (Mol Dev Evol) 2009; 312.

32. Eswarakumar VP, Lax I, Schlessinger J. Cellular signaling by fibroblast growth factor receptors. Cytokine Growth Factor Rev 2005; 16:139-49.

33. Schlessinger J. Cell signaling by receptor tyrosine kinases. Cell 2000; 103:211-25.

34. Orr-Urtreger A, Bedfort MT, Burakova T, Arman E, Zimmer Y, Givol D, et al. Developmental localization of the splicing alternatives of fibroblast growth factor receptor-2 (FGFR2). Dev Biol 1993; 158:475-86,

35. De Giorgi V, Sestini S, Massi D, Ghersetich I, Lotti T. Keratinocyte growth factor receptors. Dermatol Clin 2007; 25:477-85.

36. Danilenko DM, Ring BD, Yanagihara D, Benson W, Wiemann B, Starnes CO, Pierce GF Keratinocyte growth factor is an important endogeneous mediator of hair follicle growth development, and differentiation. Normalization of the nu/nu follicular differentiation defect and amelioration of chemotherapy-induced alopecia. Am J Pathol 1995; 147:145-54.

37. Grose R, Fantl V, Werner S, Chioni AM, Jarosz M, Rudling R, et al. The role of fibroblast growth factor receptor $2 \mathrm{~b}$ in skin homeostasis and cancer development. EMBO J 2007; 26:1268-78.

38. Yeh BK, Igarashi M, Eliseenkova AV, Plotnikov AN, Sher I, Ron D, et al. Structural basis by which alternative splicing confers specificity in fibroblast growth factor receptors. Proc Nat Acad Sci USA 2003; 100:2266-71.

39. De Moerlooze L, Spencer-Dene B, Revest J, Hajihosseini M, Rosewell I, Dickson C. An important role for the IIIb isoform of fibroblast growth factor receptor 2 (FGFR2) in mesenchymal-epithelial signalling during mouse organogenesis. Development 2000; 127:483-92.
40. Mohammadi M, Dikic I, Sorokin A, Burgess WH, Jaye M, Schlessinger J. Identification of six novel autophosphorylation sites on fibroblast growth factor receptor 1 and elucidation of their importance in receptor activation and signal transduction. Mol Cell Biol 1996; 16:977-89.

41. Ong SH, Lim YP, Low BC, Guy GR. SHP2 associates directly with tyrosine phosphorylated p90 (SNT) protein in FGF-stimulated cells. Biochem Biophys Res Commun 1997; 238:261-6.

42. Ong SH, Guy GR, Hadari YR, Laks S, Gotoh N, Schlessinger J, Lax I. FRS2 proteins recruit intracellular signaling pathways by binding to diverse targets on fibroblast growth factor and nerve growth factor receptors. Mol Cell Biol 2000; 20:979-89.

43. Kouhara H, Hadari YR, Spivak-Kroizman, Schilling JR, Bar-Sagi D, Lax I, Schlessinger J. A lipid-anchored Grb2-binding protein that links FGF-receptor activation to the Ras/ MAPK signaling pathway. Cell 1997; 89:693-702.

44. Hadari YR, Kouhara H, Lax I, Schlessinger J. Binding of Shp2 tyrosine phosphatase to FRS2 is essential for fibroblast growth factor-induced PC12 cell differentiation. Mol Cell Biol 1998; 18:3966-73.

45. Wong A, Lamothe B, Lee A, Schlessinger J, Lax I. FRS2 alpha attenuates FGF receptor signaling by Grb2-mediated recruitment of the ubiquitin ligase Cbl. Proc Natl Acad Sci USA 2002; 99:6684-9.

46. Luo Y, Sheng Y, Kan M, McKeehan WL. Control of fibroblast growth factor (FGF)7and FGF1-induced mitogenesis and downstream signaling by distinct heparin octasaccaride motifs. J Biol Chem 2006; 281:21052-61.

47. Lomri A, Lemonnier J, Delannoy P, Marie PJ. Increased expression of protein kinase $\mathrm{C} \alpha$, interleukin-1 $\alpha$ and RhoA guanosine 5'-triphsophatase in osteoblasts expressing the Ser252Trp fibroblast growth factor 2 Apert mutation: identification by analysis of complementary DNA microarray. J Bone Miner Res 2001; 16:705-12.

48. Tsang M, Dawid IB. Promotion and attenuation of FGF signaling through the RasMAPK pathway. Sci STKE 2004; 17.

49. Ahmed Z, Schuller AC, Suhling K, Tregidko C, Ladbury JE. Extracellular point mutations in FGFR2 elicit unexpected changes in intracellular signalling. Biochem J 2008; 413:37-49.

50. Belleudi F, Leone L, Nobili V, Raffa S, Francescangeli F, Maggio M, et al. Keratinocyte growth factor receptor ligands target the receptor to different intracellular pathways. Traffic 2007; 8:1854-72.

51. Belleudi F, Leone L, Aimati L, Stirparo MG, Cardinali G, Marchese C, et al. Endocytotic pathways and biological effects induced by UVB-dependent or ligand-dependent activation of the keratinocyte growth factor receptor. FASEB J 2005; 20:395-7.

52. Passos-Bueno MR. Genetics of craniosynostosis: genes, syndromes, mutations and genotype-phenotype correlations. In: Rice DP, ed. Craniofacial suture development, disease and treatment. Basel: Karger 2008:107-43.

53. Wilkie AOM, Slaney SF, Oldridge M, Poole MD, Ashworth GJ, Hockley AD, et al. Apert syndrome results from localized mutations of FGFR2 and is allelic with Crouzon syndrome. Nat Gen 1995; 9:165-72.

54. Anderson J, Burns HD, Enriquez-Harris P, Wilkie AO, Heath JK. Apert syndrome mutations in fibroblast growth factor receptor 2 exhibit increased affinity for FGF ligand. Hum Molec Genet 1998; 7:1475-83.

55. Ibrahimi OA, Eliseekova AV, Plotnikov AN, Yu K, Ornitz DM, Mohammadi M. Structural basis for fibroblast growth factor receptor 2 activation in Apert syndrome. Proc Nat Acad Sci USA 2001; 98:7182-7.

56. Slaney SF, Oldrige M, Hurst JA, Moriss-Kay GM, Hall CM, Poole MD, Wilkie AO. Differential effects of FGFR2 mutations on syndactyly and cleft palate in Apert. syndrome. Am J Hum Genet 1996; 58:923-32.

57. Lajeunie E, Cameron R, El Ghouzzi V, de Parseval N, Journeau P, Gonzales M, et al. Clinical variability in patients with Apert's syndrome. J Neurosurg 1999; 90:443-7.

58. Moloney DM, Slaney SF, Oldridge M, Wall SA, Sahlin P, Stenman G, Wilkie AO. Exclusive paternal origin of new mutations in Apert syndrome. Nature Genet 1996; 13:48-53.

59. Park WJ, Meyers GA, Li X, Theda C, Day D, Orlow SJ, et al. Novel FGFR2 mutations in Crouzon and Jackson-Weiss syndromes show allelic heterogeneity and phenotypic variability. Hum Mol Genet 1995; 4:1229-33.

60. Yu K, Herr AB, Waksman G, Ornitz DM. Loss of fibroblast growth factor receptor 2 ligandbinding specificity in Apert syndrome. Proc Nat Acad Sci USA 2000; 97:14536-41.

61. Ibrahimi OA, Zhang F, Eliseenkova AV, Itoh N, Linhardt RJ, Mohammadi M. Biochemical analysis of pathogenic ligand-dependent FGFR2 mutations suggests distinct pathophysiological mechanisms for craniofacial and limb abnormalities. Hum Mol Genet 2004; 13:2313-24.

62. Glaser RL, Broman KW, Schulman RL, Eskenazi B, Wyrobek AJ, Jabs EW. The paternalage effect in Apert syndrome is due, in part, to the increased frequency of mutations in sperm. Am J Hum Genet 2003; 73:939-47.

63. Pellegrini L, Burke DF, von Delft F, Mulloy B, Blundell TL. Crystal structure of fibroblast growth factor receptor ectodomain bound to ligand and heparin. Nature 2000; 407:1029-34.

64. Wang Y, Xiao R, Yang F, Karim BO, Iacovelli AJ, Cai J, et al. Abnormalities in cartilage and bone development in Apert syndrome FGFR2 ${ }^{+} / \mathrm{S} 252 \mathrm{~W}$ mouse. Development 2005; 132:3537-48. 
65. Shukla V, Coumoul X, Wang RH, Kim HS, Deng CX. RNA interference and inhibition of MEK-ERK signaling prevent abnormal skeletal phenotypes in a mouse model of craniosynostosis. Nature Genet 2007; 39:1145-50.

66. Munro CS, Wilkie AOM. Epidermal mosaicism producing localized acne: somatic mutation in FGFR2. Lancet 1998; 352:704-5.

67. Melnik B, Vakilzadeh F, Aslanidis C, Schmitz G. Unilateral segmental acneiform nevusa model disorder towards understanding FGFR2 function in acne. Br J Dermatol 2008; 158:1397-9.

68. Kurokawa I, Nakai Y, Nishimura K, Hakamada A, Isoda K, Yamanaka K, et al. Cytokeratin and fillagrin expression in nevus comedonicus. J Cutan Pathol 2007; 34:338-41.

69. Margolis S, Siegel IM, Choy A, Breinin GM. Depigmentation of hair, skin and eyes associated with the Apert syndrome. Birth Defects 1978; 14:341-60.

70. Kawano M, Komi-Kuramochi A, Asada M, Suzuki M, Oki J, Jiang J, Imamura T. Comprehensive analysis of FGF and FGFR expression in skin: FGF18 is highly expressed in hair follicles and capable of inducing anagen from telogen stage hair follicles. J Invest Dermatol 2005; 124:877-85.

71. Cardinali G, Ceccarelli S, Kovacs D, Aspite N, Lotti LV, Torrisi MR, Picardo M. Keratinocyte growth factor promotes melanosome transfer to keratinocytes. J Invest Dermatol 2005; 125:1190-9.

72. Hivnor CM, Yan AC, Honig PJ. Acne arising in an epidermal nevus. Pediatr Dermatol $2007 ; 24: 534-5$.

73. Melnik BC, Schmitz G, Zouboulis CC. Anti-acne agents attenuate FGFR2 signal transduction in acne. J Invest Dermatol 2009; 129:1868-77.

74. Cuerda E, Del Pozo J, Rodrìguez-Lozano J, Peña-Penabad C, Fonseca E. Acne in Apert's syndrome: treatment with isotretinoin. J Dermatol Treat 2003; 14:43-5.

75. Gilaberte M, Puig L, Alomar A. Isotretinoin treatment of acne in a patient with Apert syndrome. Pediatr Dermatol 2003; 20:443-6.

76. Benjamin LT, Trowers AB, Schachner LA. Successful acne management in Apert syndrome twins. Pediatr Dermatol 2005; 22:561-5.

77. DeGiovanni CV, Jong C, Woollons A. What syndrome is this? Pediatr Dermatol 2007; 24:186-8.

78. George FW, Peterson KG. 5 $\alpha$-Dihydrotestosterone formation is necessary for embryogenesis of the rat prostate. Endocrinology 1988; 122:1159-64.

79. Siiteri PK, Wilson JD. Testosterone formation and metabolism during male sexual differentiation in the human embryo. J Clin Endocrinal Metab 1974; 38:113-25.

80. Marker PC, Donjacour AA, Dahiya R, Cunha GR. Hormonal, cellular and molecular control of prostatic development. Dev Biol 2003; 253:165-74.

81. Cunha GR, Donjacour AA, Cooke PS, Mee S, Bigsby RM, Higgins SJ, Sugimura Y. The endocrinology and developmental biology of the prostate. Endo Rev 1987; 8:338-63.

82. Yan G, Fukabori Y, Nikolaropoulos S, Wang F, McKeehan WL. Heparin-binding keratinocyte growth factor is a candidate stromal-to-epithelial-cell andromedin. Mol Endocrinol 1992; 6:2123-8.

83. Planz B, Wang Q, Kirley SD, Lin CW, McDougal WS. Androgen responsiveness of stromal cells of the human prostate: regulation of cell proliferation and keratinocyte growth factor by androgen. J Urol 1998; 160:1850-5.

84. Alarid ET, Rubin JS, Young P, Chedid M, Ron D, Aaronson SA, Cunha GR. Keratinocyte growth factor functions in epithelial induction during seminal vesicle development. Proc Natl Acad Sci USA 1994; 91:1074-8.

85. Thomson AA, Cunha GR. Prostatic growth and development are regulated by FGF10. Development 1999; 126:3693-701.

86. Pu Y, Huang L, Birch L, Prins GS. Androgen regulation of prostate morphoregulatory gene expression: Fgf10-dependent and -independent pathways. Endocrinology 2007; 148:1697-706.

87. Lin Y, Liu G, Zhang Y, Hu YP, Yu K, Lin C, et al. Fibroblast growth factor receptor 2 tyrosine kinase is required for prostatic morphogenesis and the acquisition of strict androgen dependency for adult tissue homeostasis. Development 2007; 134:723-34.

88. Kuslak SL, Thielen JL, Marker PC. The mouse seminal vesicle shape mutation is allelic with Fgfr2. Development 2007; 134:557-65.

89. Revest JM, Spencer-Dene B, Kerr K, De Moerlooze L, Rosewell I, Dickson C. Fibroblast growth factor receptor 2-IIIb acts upstream of Shh and Fgf4 and is required for limb bud maintenance but not for the induction of Fgf8, Fgf10, Msx1, Bmp4. Dev Biol 2001; 231:47-62.

90. Celli G, LaRochelle WJ, Mackem S, Sharp R, Merlino G. Soluble dominant-negative receptor uncovers essential roles for fibroblast growths factors in multi-organ induction and patterning. EMBO J 1998; 17:1642-55.

91. Min H, Danilenko DM, Scully SA, Bolon B, Ring BD, Tarpley JE, et al. Fgf-10 is required for both limb and lung development and exhibits striking functional similarity to Drosophila branchless. Genes Dev 1998; 12:3156-61.

92. Sekine K, Ohuchi H, Fujiwara M, Yamasaki M, Yoshizawa T, Sato T, et al. Fgf10 is essential for limb and lung formation. Nat Genet 1999; 21:138-41.

93. Petiot A, Conti FJ, Grose R, Revest JM, Hodivala-Dilke KM, Dickson C. A crucial role for Fgfr2-IIIb signalling in epidermal development and hair follicle patterning. Development 2003; 130:5493-501.
94. Werner S, Smola H, Liao X, Longaker MT, Krieg T, Hofschneider PH, Williams LT. The function of KGF in morphogenesis of epithelium and reepithelialization of wounds. Science 1994; 266:819-22.

95. Mikkola ML. p63 in skin appendage development. Cell Cycle 2007; 6:285-90.

96. Mailleux AA, Spencer-Dene B, Dillon C, Ndiaye D, Savona-Baron C, Itoh N, et al. Role of FGF10/FGFR2b signaling during mammary gland development in the mouse embryo. Development 2002; 130:5493-501.

97. Mills AA, Zheng B, Wang XJ, Vogel H, Roop DR, Bradley A. p63 is a p53 homologue required for limb and epidermal morphogenesis. Nature 1999; 398:708-13.

98. Yang A, Schweitzer R, Sun DQ, Kaghad M, Walker N, Bronson RT, et al. p63 is essential for regenerative proliferation in limb, craniofacial and epidermal development. Nature 1999; 398:714-8.

99. Rice R, Spencer-Dene B, Connor EC, Gritli-Linde A, McMahon AP, Dickson C, et al. Disruption of Fgf10/Fgfr2b-coordinated epithelial-mesenchymal interactions causes cleft palate. J Clin Invest 2004; 113:1692-700.

100. Allen M, Grachtchouk M, Sheng H, Grachtchouk V, Wang A, Wei L, et al. Hedgehog signaling regulates sebaceous gland development. Am J Pathol 2003; 163:2173-8.

101. Riobo NA, Manning DR. Pathway of signal transduction employed by vertebrate hedgehogs. Biochem J 2007; 403:369-79.

102. Niemann C, Unden AB, Lyle S, Zouboulis ChC, Toftgård R, Watt FM. Indian hedgehog and $\beta$-catenin signaling: role in the sebaceous lineage of normal and neoplastic mammalian epidermis. Proc Natl Acad Sci USA 2003; 100:11837-80.

103. Porter DF. Cholesterol precursors and facial clefting. J Clin Invest 2006; 116:2322-5.

104. Kalff-Suske M, Wild A, Topp J. Point mutations throughout the Gli3 gene cause Greig cephalopolysyndactyly syndrome. Hum Mol Genet 1999; 8:1769-77.

105. Bitgood MJ, McMahon AP. Hedgehog and Bmp genes are coexpressed at many diverse sites of cell-cell interaction in the mouse embryo. Dev Biol 1995; 172:126-38.

106. Iseki S, Araga A, Ohuchi H, Nohno T, Yoshioka H, Hayashi F, Noji S. Sonic hedgehog is expressed in epithelial cells during development of whisker, hair and tooth. Biochem Biophys Res Commun 1996; 218:688-93.

107. Kalderon D. Transducing the hedgehog signal. Cell 2000; 103:371-4.

108. Matise MP, Joyner AL. Gli genes in development of cancer. Oncogene 1999; 18:7852-9.

109. Ruiz I, Altaba B, Sanchez P, Dahmane N. Gli and hedgehog in cancer: tumors, embryos and stem cells. Nat Rev Caner 2002; 2:361-72.

110. St-Jacques B, Dassule HR, Karavanova I, Botchkarev VA, Li J, Danielian PS, et al. Sonic hedgehog signaling is essential for hair development. Curr Biol 1998; 8:1058-68.

111. Chiang C, Swan RZ, Grachtchouk M, Bolinger M, Litingtung Y, Robertson EK, et al Essential role for sonic hedgehog during hair follicle morphogenesis. Dev Biol 1999; 205:1-9.

112. Zhang L, Li W-H, Anthonavage M, Eisinger M. Melanocortin-5 receptor: a marker of human sebocyte differentiation. Peptides 2006; 27:413-20.

113. Zouboulis CC. Sebaceous gland receptors. Dermato-Endocrinol 2009; 1:1-4.

114. Chen W, Kelly MA, Opitz-Araya X, Thomas RE, Low MJ, Cone RD. Exocrine gland dysfuction in MC5R-deficient mice: evidence for coordinated regulation of exocrine gland function by melanocortin peptides. Cell 1997; 91:789-98.

115. Thody AJ, Shuster S. Control of sebaceous gland function in the rat by alpha-melanocyte-stimulating hormone. J Endocrinol 1975; 64:503-10.

116. Thody AJ, Cooper MF, Bowden PE, Meddis D, Shuster S. Effect of alpha-melanocytestimulating hormone and testosterone on cutaneous and modified sebaceous glands in the rat. J Endocrinol 1976; 71:279-88.

117. Böhm M, Luger TA, Tobin DJ, García-Borrón JC. Melanocortin receptor ligands: new horizons for skin biology and clinical dermatology. J Invest Dermatol 2006; 126:1966-75.

118. Zhang L, Anthonavage M, Huang Q, Li WH, Eisinger M. Proopiomelanocortin peptides and sebogenesis. Ann NY Acad Sci 2003; 994:154-61.

119. Deplewski D, Rosenfield RL. Role of hormones in pilosebaceous unit development Endocr Rev 2000; 21:363-92.

120. Nelson AM, Gilliland KL, Cong Z, Thiboutot DM. 13-cis retinoic acid induces apoptosis and cell cycle arrest in human SEB-1 sebocytes. J Invest Dermatol 2006; 126:2178-89.

121. Goyette P, Allan D, Peschard P, Chen CF, Wang W, Lohnes D. Regulation of Gli activity by all-trans retinoic acid in mouse keratinocytes. Cancer Res 2000; 60:5386-9.

122. Kasper M, Schnidar H, Neill GW, Hanneder M, Klingler S, Blaas L, et al. Selective modulation of Hedgehog/GLI target gene expression by epidermal growth factor signaling in human keratinocytes. Mol Cell Biol 2006; 26:6283-99.

123. Bigelow RL, Jen EY, Delehedde M, Chari NS, McDonnell TJ. Sonic hedgehog induces epidermal growth factor dependent matrix infiltration in $\mathrm{HaCaT}$ keratinocytes. J Invest Dermatol 2005; 124:457-65.

124. Kessaris N, Jamen F, Rubin L, Richardson WD. Cooperation between sonic hedgehog and fibroblast growth factor/MAPK signalling pathways in neocortical precursors. Development 2004; 131:1289-98.

125. Lupo G, Liu Y, Qiu R, Chandraratna RA, Barsacchi G, He RQ, Harris WA. Dorsoventral patterning of the Xenopus eye: a collaboration of retinoid, hedgehog and FGF receptor signaling. Development 2005; 132:1737-48. 
126. Palma V, Lim DA, Dahmane N, Sánchez P, Brionne TC, Herzberg CD, et al. Sonic hedgehog controls stem cell behavior in the postnatal and adult brain. Development 2005; 132:335-44

127. Palma V, Ruiz I, Altaba A. Hedgehog-GLI signaling regulates the behavior of cells with stem cell properties in the developing neocortex. Development 2004; 131:337-45.

128. Riobo NA, Haines GM, Emerson CP. Protein kinase C-delta and mitogen-activated protein/extracellular signal-regulated kinase-1 control GLI activation in hedgehog signaling. Cancer Res 2006; 66:839-45.

129. Riobo NA, Lu K, Ai X, Haines GM, Emerson CP Jr. Phosphoinositide 3-kinase and Akt are essential for sonic hedgehog signaling. Proc Nat Acad Sci USA 2006; 103:4505-10.

130. Kartasova T, Scandurro AB, Denning MF, Wirth PJ, Yuspa SH, Lichti U. Factors mediating the interactions between epidermal and dermal cells in skin grafts that might be important for hair follicle development. J Invest Dermatol 1995; 104:21-2.

131. Prouty SM, Lawrence L, Stenn KS. Fibroblast-dependent induction of a murine skin lesion similar to human nevus sebaceous of Jadassohn. Lab Invest 1997; 76:179-89.

132. Barbieri CE, Barton CE, Pietenpol JA. $\triangle \mathrm{Np} 63 \alpha$ expression is regulated by the phosphoinositide 3-kinase pathway. J Biol Chem 2003; 278:51408-41.

133. Miki T, Bottaro DP, Fleming TP, Smith CL, Burgess WH, Chan AM, Aaronson SA. Determination of ligand-binding specificity by alternative splicing: two distinct growth factor receptors encoded by a single gene. Proc Natl Acad Sci USA 1992; 89:246-50.

134. Candi E, Rufini A, Terrinoni A, Giamboi-Miraglia A, Lena AM, Mantovani R, et al. $\triangle \mathrm{Np} 63$ regulates thymic development through enhanced expression of FgfR2 and Jag2. Proc Natl Acad Sci USA 2007; 104:11999-2004.

135. Wheatley VR. Biochemical aspects of sebum formation. In: The Physiology and Pathophysiology of the Skin. The Sebaceous Gland. Vol 9, chapt 91, Academic Press London 1986; 2873-98.

136. D'Erchia AM, Tullo A, Lefkimmiatis K, Saccone C, Sbisà E. The fatty acid synthase gene is a conserved p53 family target from worm to human. Cell Cycle 2006; 5:750-8.

137. Daub H, Weisss FU, Wallasch C, Ullrich A. Role of transactivation of EGF receptor in signaling by $\mathrm{G}$ protein-coupled receptors. Nature 1996; 379:557-60.

138. Schlessinger J. Common and distinct elements in cellular signaling via EGF and FGF receptors. Science 2004; 306:1506-7.

139. Kaushansky A, Gordus A, Chang B, Rush J, MacBeath G. A quantitative study of the recruitment potential of all intracellular tyrosine residues on EGFR, FGFR1 and IGF1R. Mol BioSyst 2008; 4:643-53.

140. Hsieh T, Ho N. Resolution of acne following therapy with an oral contraceptive in a patient with Apert syndrome. J Am Acad Dermatol 2005; 53:173-4.

141. Lefkowitz A, Schwartz RA, Lambert WC. Nevus comedonicus. Dermatology 1999; 199:204-7.

142. Guldbakke KK, Khachemoune A, Deng A, Sina B. Naevus comedonicus: a spectrum of body involvement. Clin Exp Dermatol 2007; 32:488-92.

143. Bongiorno MR, Pistone G, Arico M. Naevus comedonicus: immunohistochemical features in two cases. Acta Derm Venereol 2003; 83:300-1.

144. Schröder JM. Cytokine networks in the skin. J Invest Dermatol 1995; 105:20-4.

145. Plewig G, Fulton JE, Kligman AM. Cellular dynamics of comedo formation in Acne vulgaris. Arch Dermatol Forsch 1971; 242:12-29.

146. Faiman C, Winter JSD. Gonadotrophins and sex hormone patterns in puberty: clinical data. In: Grumbach MM, Grave GD, Mayer FE, et al (eds)., Control of the onset of puberty. John Wiley \& Sons NY 1974; 33-5.

147. Dlugosz AA, Cheng C, Denning MF, Dempsey PJ, Coffey RJ Jr, Yuspa SH. Keratinocyte growth factor receptor ligands induce transforming growth factor $\alpha$ expression and activate epidermal growth factor receptor signaling pathway in cultured epidermal keratinocytes. Cell Growth Diff 1994; 5:1283-92.

148. Guy R, Kealy T. The effects of inflammatory cytokines on the isolated human sebaceous infundibulum. J Invest Dermatol 1998; 110:410-5.

149. Aldana OL, Holland DB, Cunliffe WJ. Variation in pilosebaceous duct keratinocyte proliferation in acne patients. Dermatology 1998; 196:98-9.

150. Jeremy AH, Holland DB, Roberts SG, Thomson KF, Cunliffe WJ. Inflammatory events are involved in acne lesion initiation. J Invest Dermatol 2003; 121:20-7.

151. Mee JB, Antonopoulos C, Poole S, Kupper TS, Groves RW. Counter-regulation of interleukin $1 \alpha$ (IL-1 $\alpha)$ and IL-1 receptor antagonist in murine keratinocytes. J Invest Dermatol 2005; 124:1267-74.

152. Hammerberg C, Bata-Csorgo Z, Voorhees JJ, Cooper KD. Il-1 and IL-1 receptor antagonist regulation during keratinocyte cell cycle and differentiation in normal and psoriatic epidermis. Arch Dermatol Res 1998; 290:367-74.

153. Freedberg IM, Tomic-Canic M, Komine M, Blumenberg M. Keratins and the keratinocyte activation cycle. J Invest Dermatol 2001; 116:633-40.

154. Kurokawa I, Mayer-da-Silva A, Gollnick H, Orfanos CE. Monoclonal antibody labeling for cytokeratins and filaggrin in the human pilosebaceous unit of normal, seborrhoeic and acne skin. J Invest Dermatol 1988; 91:566-71.

155. Hughes BR, Morris C, Cunliffe WJ, Leigh IM. Keratin expression in pilosebaceous epithelia in truncal skin of acne patients. Br J Dermatol 1996; 134:247-56.

156. Komine M, Rao LS, Freedberg IM, Simon M, Milisavljevic V, Blumenberg M. Interleukin-1 induces transcription of keratin 6 in human epidermal keratinocytes. J Invest Dermatol 2001; 116:330-8.
157. Groves RW, Sherman L, Mizutani H, Dower SK, Kupper TS. Detection of interleukin-1 receptors in human epidermis. Induction of the type II receptor after organ culture and in psoriasis. Am J Pathol 1994; 145:1048-56.

158. Groves RW, Mizutani H, Kieffer JD, Kuppers TS. Inflammatory skin disease in transgenic mice that express high levels of interleukin-1alpha in basal epidermis. Proc Natl Acad Sci USA 1995; 92:11874-8.

159. Holland DB, Aldana OL, Cunliffe WJ. Abnormal integrin expression in acne. J Invest Dermatol 1998; 110:559.

160. Gan L, Li L. Regulations and roles of the interleukin-1 receptor associated kinases (IRAKs) in innate and adaptive immunity. Immun Res 2006; 35:295-302.

161. Fusenig NE. Epithelial-mesenchymal interactions regulate keratinocyte growth and differentiation in vitro. In: Leigh I, Lane B, Watt F, eds. The Keratinocyte Handbook. Cambridge: Cambridge University Press 1994; 71-94.

162. Smola H, Thiekötter G, Fusenig NE. Mutual induction of growth factor gene expression by epidermal-dermal cell interaction. J Cell Biol 1993; 122:417-29.

163. Werner S. Keratinocyte growth factor: a unique player in epithelial repair processes. Cytokine Growth Factor Rev 1998; 9:153-65.

164. Maas-Szabowski N, Stark HJ, Fusenig NE. Keratinocyte growth regulation in defined organotypic cultures through IL-1-induced keratinocyte growth factor expression in resting fibroblasts. J Invest Dermatol 2000; 114:1075-84.

165. Szabowski A, Maas-Szabowski N, Andrecht S, Kolbus A, Schorpp-Kistner M, Fusenig NE, Angel P. c-Jun and JunB antagonistically control cytokine-regulated mesenchymalepidermal interaction in skin. Cell 2000; 103:745-55.

166. Boehm KD, Yun JK, Strohl KP, Elmets CA. Messenger RNAs for the multifunctional cytokines interleukin-1alpha, interleukin-1beta and tumor necrosis factor-alpha are present in adnexal tissues and in dermis of normal human skin. Exp Dermatol 1995; 4:335-41.

167. Anttila HIS, Reitamo S, Saurat J-H. Interleukin 1 immunoreactivity in sebaceous glands. Br J Dermatol 1992; 127:585-8.

168. Thielitz A, Reinhold D, Vetter R, Bank U, Helmuth M, Hartig R, et al. Inhibitors of dipeptidyl peptidase IV and aminopeptidase $\mathrm{N}$ target major pathogenic steps in acne initiation. J Invest Dermatol 2007; 127:1042-51.

169. Glick AB, Flanders KC, Danielpour D, Yuspa SH, Sporn MB. Retinoic acid induces transforming growth factor-beta 2 in cultured keratinocytes and mouse epidermis. Cell Regul 1989; 1:87-97.

170. Singh B, Murphy RF, Ding XZ, Roginsky AB, Bell RH Jr, Adrian TE. On the role of transforming growth factor- $\beta$ in the growth inhibitory effects of retinoic acid in human pancreatic cancer cells. Mol Cancer 2007; 6:82.

171. El-Metwally TH, Adrian TE. Optimization of treatment conditions for studying the anticancer effects of retinoids using pancreatic adenocarcinoma as a model. Biochem Biophys Res Commun 1999; 257:596-603

172. Foitzik K, Spexard T, Nakamura M, Halsner U, Paus R. Towards dissecting the pathogenesis of retinoid-induced hair loss: all-trans retinoic acid induces premature hair follicle regression (catagen) by upregulation of transforming growth factor- $\beta_{2}$ in the dermal papilla. J Invest Dermatol 2005; 124:1119-26.

173. Ding W, Shi W, Bellusci S, Groffen J, Heisterkamp N, Minoo P, Warburton D. Sprouty2 downregulation plays a pivotal role in mediating crosstalk between TGF $\beta_{1}$ signaling and EGF as well FGF receptor tyrosine kinase-ERK pathways in mesenchymal cells. J Cell Physiol 2007; 212:796-806.

174. Cara JF, Rosenfield RL, Furlanetto RW. A longitudinal study of the relationship of plasma somatomedin-C concentration to the pubertal growth spurt. Am J Dis Child 1987; 141:562-4.

175. Aizawa H, Niimura M. Elevated serum insulin-like growth factor-1 (IGF-1) levels in women with postadolescent acne. J Dermatol 1995; 22:249-52.

176. Cappel M, Mauger D, Thiboutot D. Correlation between serum levels of insulin-like growth factor 1, dehydroepiandrosterone sulfate, and dihydrotestosterone and acne lesion counts in adult women. Arch Dermatol 2005; 141:333-8.

177. Vora S, Ovhal A, Jerajani H, Nair N, Chakrabortty A. Correlation of facial sebum to serum insulin-like growth factor-1 in patients with acne. Br J Dermatol 2008; 159:979-95.

178. Horton R, Pasupuletti V, Antonipillai I. Androgen induction of $5 \alpha$-reductase may be mediated via insulin-like growth factor-I. Endocrinology 1993; 133:447-51.

179. Belgorosky A, Baquedano MS, Guerico G, Rivarola MA. Adrenarche: postnatal adrenal zonation and hormonal and metabolic regulation. Horm Res 2008; 70:257-67.

180. Cara JF. Insulin-like growth factors, insulin-like growth factor binding proteins and ovarian androgen production. Horm Res 1994; 42:49-54

181. Berensztein EB, Baquedano MS, Pepe CM, Costanzo M, Saraco NI, Ponzio R, et al. Role of IGFs and insulin in the human testis during postnatal activation: differentiation of steroidogenic cells. Pediatr Res 2008; 63:662-6.

182. Fan W, Yanase T, Morinaga H, Okabe T, Nomura M, Daitoku H, et al. Insulin-like growth factor 1 /insulin signaling activates androgen signaling through direct interactions of Foxo1 with androgen receptor. J Biol Chem 2007; 282:7329-38.

183. Downie MM, Sanders DA, Kealey T. Modelling the remission of individual acne lesions in vitro. Br J Dermatol 2002; 147:869-78.

184. Smith TM, Cong Z, Gilliland KL, Clawson GA, Thiboutot DM. Insulin-like growth factor-1 induces lipid production in human SEB-1 sebocytes via sterol response elementbinding protein-1. J Invest Dermatol 2006; 126:1226-32. 
185. Östman EM, Liljeberg Elmstahl HGM, Björck IME. Inconsistency between glycemic and insulinemic responses to regular and fermented milk products. Am J Clin Nutr 2001; 74:96-100.

186. Hoyt G, Hickey MS, Cordain L. Dissociation of the glycaemic and insulinaemic responses to whole and skimmed milk. Br J Nutr 2005; 93:175-7.

187. Melnik BC. Milk consumption: aggravating factor of acne and promoter of chronic diseases of Western societies. J Dtsch Dermatol Ges 2009; 7:1-10.

188. Smith R, Mann N, Braue A, Mäkeläinen H, Varigos GA. The effect of a high protein, low glycemic load diet versus a conventional, high glycemic load diet on biochemical parameters associated with Acne vulgaris. J Am Acad Dermatol 2007; 57:247-56.

189. Smith R, Mann N, Mäkeläinen H, Roper J, Braue A, Varigos G. A pilot study to determine the short-term effects of a low glycemic load diet on hormonal markers of acne: a nonrandomized, parallel, controlled feeding trial. Mol Nutr Food Res 2008; 52:718-26.

190. Melnik B, Schmitz G. FGFR2 signaling and the pathogenesis of acne. J Dtsch Derm Ges 2008; 6:721-8.

191. Schroeder M, Zouboulis CC. All-trans-retinoic acid and 13-cis-retinoic acid: pharmacokinetics and biological activity in different cell culture models of human keratinocytes. Horm Metab Res 2007; 39:136-40.

192. Sepp-Lorenzino L. Structure and function of the insulin-like growth factor I receptor. Breast Cancer Res Treat 1998; 47:235-53.

193. Nantermet P, Xu J, Yu Y, Hodor P, Holder D, Adamski S, et al. Identification of genetic pathways activated by the androgen receptor during the induction of proliferation in the ventral prostate gland. J Biol Chem 2004; 279:1310-22.

194. Le H, Arnold JT, McFann KK, Blackman MR. DHT and testosterone, but not DHEA or E2, differentially modulate IGF-I, IGFBP-2 and IGFBP-3 in human prostatic stromal cells. Am J Physiol Endocrin Metab 2006; 290:952-60.

195. Goldstein JL, DeBose-Boyd RA, Brown MS. Protein sensors for membrane sterols. Cell 2006; 124:35-46.

196. Chang Y, Wang L, Lu X, Thewke DP, Mason RJ. KGF induces lipogenic genes through a PI3K and JNK/SREBP-1 pathway in H292 cells. J Lipid Res 2005; 46:2624-35.

197. Smith TM, Gilliland K, Clawson GA, Thiboutot D. IGF-1 induces SREBP-1 expression and lipogenesis in SEB-1 sebocytes via activation of the phosphoinositide 3-kinase/Akt pathway. J Invest Dermatol 2008; 128:1286-93.

198. Rosignoli C, Nicolas JC, Jomard A, Michel S. Involvememt of the SREBP pathway in the mode of action of androgens in sebaceous glands in vivo. Exp Dermatol 2003; 12:480-9.

199. Passi S, Picardo M, Nazzaro-Porro M, Breathnach A, Confaloni AM, Serlupi-Crescenzi G. Antimitochondrial effect of saturated medium chain length (C8-C13) dicarboxylic acids. Biochem Pharmacol 1994; 33:103-8.

200. Vidal A, Sabatini M, Rolland-Valognes G, Renard P, Madelmont JC, Mounetou E. Synthesis and in vitro evaluation of targeted tetracycline derivatives: effects on inhibition of matrix metalloproteinases. Bioorganic Medicinal Chemistry 2007; 15:2368-74.

201. Ding W, Bellusci S, Shi W, Warburton D. Functional analysis of the human Sprouty2 gene promoter. Gene 2003; 322:175-85.

202. Yusoff P, Lao DH, Ong SH, Wong ES, Lim J, Lo TL, et al. Sprouty2 inhibits the Ras/MAP kinase pathway by inhibiting the activation of Raf. J Biol Chem 2002; 277:3195-201.

203. Paraskevaidis A, Drakoulis N, Roots I, Orfanos CE, Zouboulis CC. Polymorphisms in the human cytochrome P-450 1A1 gene (CYP1A1) as a factor for developing acne. Dermatology 1998; 196:171-5.

204. Antczak C, DeMeester I, Bauvois B. Ectopeptidases in pathophysiology. BioEssays 2001; 23:251-60.

205. Centers for Disease Control (CDC). Accutane-exposed pregnancies-California, 1999. MMWR Morb Mortal Wkly Rep 2000; 49:28-31.

206. Willhite CC, Hill RM, Irving DW. Isotretinoin-induced craniofacial malformations in human and hamsters. J Craniofac Genet Dev Biol 1986; 2:193-209.

207. Lammer EJ, Chen DT, Hoar RM, Agnish ND, Benke PJ, Braun JT, Curry CJ, et al. Retinoic acid embryopathy. N Engl J Med 1985; 313:837-41.

208. Goulding EH, Pratt RM. Isotretinoin teratogenicity in mouse whole embryo culture. J Craniofac Genet Dev Biol 1986; 6:99-112.

209. Crisera C, Teng E, Wasson KL, Heller J, Gabbay JS, Sedrak MF, et al. Formation of in vitro cleft palate by abrogation of fibroblast growth factor signaling. Plast Reconstr Surg 2008; 121:218-24.

210. Ohuchi H, Hori Y, Yamasaki M, Harada H, Sekine K, Kato S, Itoh N. FGF10 acts a major ligand for FGF receptor 2IIIb in mouse multi-organ development. Biochem Biophys Res Commun 2000; 277:643-9.

211. Arman E, Haffner-Krausz R, Gorivodsky M, Lonai P. FGFR2 is required for limb outgrowth and lung branching morphogenesis. Proc Natl Acad Sci USA 1999; 96:11895-9.

212. Warburton D, Schwarz M, Tefft D, Flores-Delgado G, Anderson KD, Cardoso WV. The molecular basis of lung morphogenesis. Mechan Dev 2000; 92:55-81.

213. Lew ED, Bae JH, Rohmann E, Wollnik B, Schlessinger J. Structural basis for reduced FGFR2 activity in LADD syndrome: implications for FGFR autoinhibition and activation. Proc Natl Acad Sci USA 2007; 104:19802-7.

214. Zouboulis CC, Eady A, Philpott M, Goldsmith LA, Orfanos C, Cunliffe WC, Rosenfield R. What is the pathogenesis of acne? Exp Dermatol 2005; 14:143-52. 